Article

\title{
Building Energy Model for Mexican Energy Standard Verification Using Physics-Based Open Studio SGSAVE Software Simulation
}

\author{
Andrés Jonathan Guízar Dena ${ }^{1} \mathbb{D}$, Miguel Ángel Pascual ${ }^{2}$ and Carlos Fernández Bandera ${ }^{1, *(D)}$ \\ 1 School of Architecture, University of Navarra, 31009 Pamplona, Spain; aguizardena@alumni.unav.es \\ 2 EFINOVATIC Certificación Energetica SL, 31192 Pamplona, Spain; mapascual@efinovatic.es \\ * Correspondence: cfbandera@unav.es; Tel.: +34-948-425-600 (ext. 803189)
}

Citation: Guízar Dena1, A.J.;

Pascual, M.Á.; Fernández Bandera, C.

Building Energy Model for Mexican

Energy Standard Verification Using

Physics-Based Open Studio SGSAVE

Software Simulation. Sustainability

2021, 13, 1521. https://doi.org/

$10.3390 /$ su13031521

Received: 23 November 2020

Accepted: 26 January 2021

Published: 1 February 2021

Publisher's Note: MDPI stays neutral with regard to jurisdictional clai$\mathrm{ms}$ in published maps and institutional affiliations.

Copyright: $\odot 2021$ by the authors. Licensee MDPI, Basel, Switzerland. This article is an open access article distributed under the terms and conditions of the Creative Commons Attribution (CC BY) license (https:// creativecommons.org/licenses/by/ $4.0 /)$.

\begin{abstract}
The aim of the project detailed in this article was the development of an energy model for verifying Mexican energy standard compliance using the energy simulation engine EnergyPlus through Open Studio SGSAVE software. We aimed to improve the tool's ability to increase the comfort of social housing through the implementation of the standard in a practical digital tool. The project followed a four-stage methodology. The first stage was the development of climatic zoning for the country. The second stage involved the research and classification of the main traditional construction systems. The third stage was extensive research on the actual state of Mexican energy verification and its legal framework. The standard studied was NOM-020-ENER-2011. The final stage was testing the verification method by introducing the energy Mexican rule into the proposed software with the zoning and construction systems catalogue. A base model of a social housing type was developed in the software. Then, this model was improved to respond to each representative climate zone. Both models were simulated and we verified if they met the requirements. The results were contrasted for determining if there were energy savings. As a conclusion, we found that the actual energy standard of Mexico needs to be changed and we suggest the implementation of the energy simulation engine Energy Plus for creating more complete reports. This will help with the practical improvements in social housing conditions.
\end{abstract}

Keywords: Mexico; energy simulation; building energy model; Open Studio; SGSAVE; NOM-020ENER-2011; climate zoning; traditional construction systems; social housing; verification method

\section{Introduction}

The low thermal comfort in social housing is becoming a severe cause of house abandonment in Mexico. The general director of the National Fund for Social Housing of Mexico (INFONAVIT), David Penchyna, declared for the digital news portal El Financiero: "There are 100 abandoned social houses. The causes are diverse, like non-payment, not enough public services, and houses that did not meet the minimum conditions of comfort" [1]. This social housing problem is the result of the lack of a comfort model, with studies only focusing on construction quality and cost. Taking, for example, the situation in another context, like the European Union, we observe that the public regulations for building construction and restoration consider the energy performance. To address the energy demands and the comfort needs for interior spaces, the European standards provide reference values for ensuring the optimal habitat conditions of buildings. Because not all the social housing owners have enough economical sources for implementing a specialized design and optimization for their particular project, it is crucial that the authorities establish a guide for building based on proper studies and customized reference values.

Some studies focused on building residential projects considering energy efficiency optimization. Griego and Krarti highlighted the importance of implementing energy optimization strategies for residential projects in the Mexican context: "The need to reduce 
domestic energy consumption is highly urgent, particularly as the number of homes in Mexico continues to increase. The awareness of this need has initiated the development of sustainability and energy efficiency guide-lines in the national residential building code, CEV. Findings from this study indicate that greater emphasis should be placed on implementing the minimum thermal insulation levels" [2].

For the last twelve years, Mexico has made a remarkable efforts to create and implement the principles of sustainability and energy savings in their laws and codes for construction and the commercialization of equipment and household appliances. In 2011, the government of Mexico published in "Diario Oficial de la Federación" (Official Journal of Mexican Federation), the first energy standard of energy efficiency for buildings: NOM-020-ENER-2011 [3]. The objectives of the norm were defined in the document: "In Mexico, the thermal conditioning of buildings has a great impact on the peak demand of the electrical system. It is greater in the northern and coastal areas of the country, where the use of cooling equipment is more common than heating. In this sense, this standard optimizes the design of the thermal behavior of the envelope, obtaining benefits like energy savings due to the reduction of the capacity of the cooling equipment" [3]. The role of building performance simulation (BPS) in electrical grid stability has been widely studied by different authors [4-6], showing the importance of making these models available from building design to operation.

The Mexican energy standards focus the scope of testing on the heat gains of the thermal envelope of the building. However, given the instability due to the constant change in political parties in charge of government leadership, the Mexican energy standard stopped its development and implementation in the regional building codes of the country. The last actualization of the standard was approved on 2013. The only tools available for the verification of the standard are a digital guide for its application and a digital tool (made in Excel) for automatic calculations by entering the numeric data in the corresponding spaces [7]. Although this tool fulfills its purpose of checking if a building satisfies the Mexican energy requirements, it only considers the total surface area and some climatology variables defined inside the documentation of the rules.

The energy standard should be analyzed by understanding the characteristics of the Mexican housing scheme. In the essay Cuantificando la clase media en México en la primera mitad del siglo XXI: un ejercicio exploratorio (Quantifying the middle class in Mexico at the first half of twenty-first century: an exploratory exercise), the authors conducted a study supported by statistics from the National Institute of Statistics and Geography (INEGI) to analyze the composition of economic classes in depth. They concluded that the highest $\%$ of the Mexican population is identified as lower class, at $55.1 \%$ of the total. The second group is composed of the middle class at $42.4 \%$, with the upper class being $2.5 \%$ of the total. Notably, according to the essay, $80 \%$ of the Mexican population lives in cities and metropolitan areas. Therefore, $78 \%$ of the population is the target market for social housing developers [8]. The construction industry is one of the strongest and most profitable economic activities in Mexico. Residential and mixed-used constructions are some of the most wanted business models for private and government investment (through the national housing fund, INFONAVIT, and other public institutes).

Although NOM-020-ENER-2011 is the only official standard designed for mandatory application, other public tools are available for enhancing energy performance and environmental strategies for sustainable architecture. The NMX-AA-164-SCFI-2013 is a code developed by the Secretariat of Agriculture and Environment (SEMARNAP) and the Mexican Chamber of Construction Industry (CMIC) for promoting environmentally friendly techniques, strategies, and technologies in construction. It is a document with several categories of different ecological aspects (water, soil, energy, materials, landscape, interior comfort, and social responsibility) and a scheme of credit fulfillment [9]. Mexico also offers economical alternatives to implementing sustainable architecture and technologies for energy savings INFONAVIT runs a public program for social housing constructors called Hipoteca Verde (Green Mortgage). With this program, the constructor can obtain a 
public loan for real estate projects if they support the application with eco-technologies: design strategies and technology for energy savings, like photovoltaic panels, solar thermal collectors, thermal insulation, and water recycling [10]. As such, there is an interest in and potential market for the implementation of energy simulation and building efficiency models (BEMs). According to the statistics published by INEGI in 2018, the biggest energy expense of the country's households is electricity. In the northern states, $40 \%$ of families use air conditioning in their houses, providing a solution to their thermal comfort needs [11]. Due to the need for mechanical air conditioning, the evaluation of the energy performance of buildings and indoor living space quality provides an opportunity reducing electrical consumption and costs while improving the well-being of users.

Given the lack of practical implementation methods for the standard (providing an opportunity to create a different and attractive proposal for the Mexican market), the collaborating enterprise decided to investigate and develop their own model for energy verification using their tools and software. The aim of this investigation was to develop a model for verifying Mexican energy standard compliance for social housing models, and to research the benefits of using the Energy Plus building energy program [12]. Demonstrating the potential for building energy savings by designing an efficient thermal envelope and applying bio-climatic strategies to the design will be a useful tool for national construction.

The first three sections explain the procedures followed and the primary results. Each section describes the principal sources studied. Then, the procedure used for developing each of the method's aims is explained in detail, and the section ends with primary conclusions. The fourth section begins with an explanation of the testing method used. Then, a quick explanation of the developed models is reported. Finally, the results section reports the simulation results with a brief analysis of each one. In the conclusions section, a list of the pending aims and topics is provided, with a final reflection on the research results.

\section{Methodology}

\subsection{Design and Phases}

Creating a new model of energy verification for Mexico seems to be a complex project. Our principal research aims were the development of a model for verifying the model's compliance with the Mexican standard and conducting a comparison with the Energy Plus simulation model for testing the benefits of including thermal comfort analysis in the verification model. For a new scheme, profound studies are required to support the coefficients and reference values of the standard. For practical purposes, the use of an actual verification method was suggested, but with the customization of several issues. Due to the lack of an international regulation code at the time (2010), the actual energy standard NOM-020-ENER-2011 was developed using the practices and guidelines quoted in publications, like the ASHRAE (American Society of Heating, Refrigerating and Air Conditioning Engineers) Fundamentals Manual, 1998 and 2001 editions. The standard presents its own method of verification, pursuing energy savings by controlling the thermal envelope heat transfer with a mathematical calculation method [13]. So, as a first approach for a new verification model, new reference values were researched and created. To obtain the planned results of the initial hypothesis, the working plan was divided into four stages,as displayed on Figure 1: (1) The development of climatologic zoning of Mexico according to its different climatic severities; (2) the study of Mexican energy standard NOM-020-ENER-2011 and its application; (3) constructing a traditional building system catalogue for the country; (4) the development of an energy testing exercise with the previous materials and tools, applied for the selected social housing model. The fourth stage, the testing exercise, was used to test if the existing model complied with the standard. If not, improved models for each climatic zone were developed until standard compliance was achieved. Finally, for verifying the applicability of energy efficiency strategies on different traditional construction systems, a comparison test was performed. 


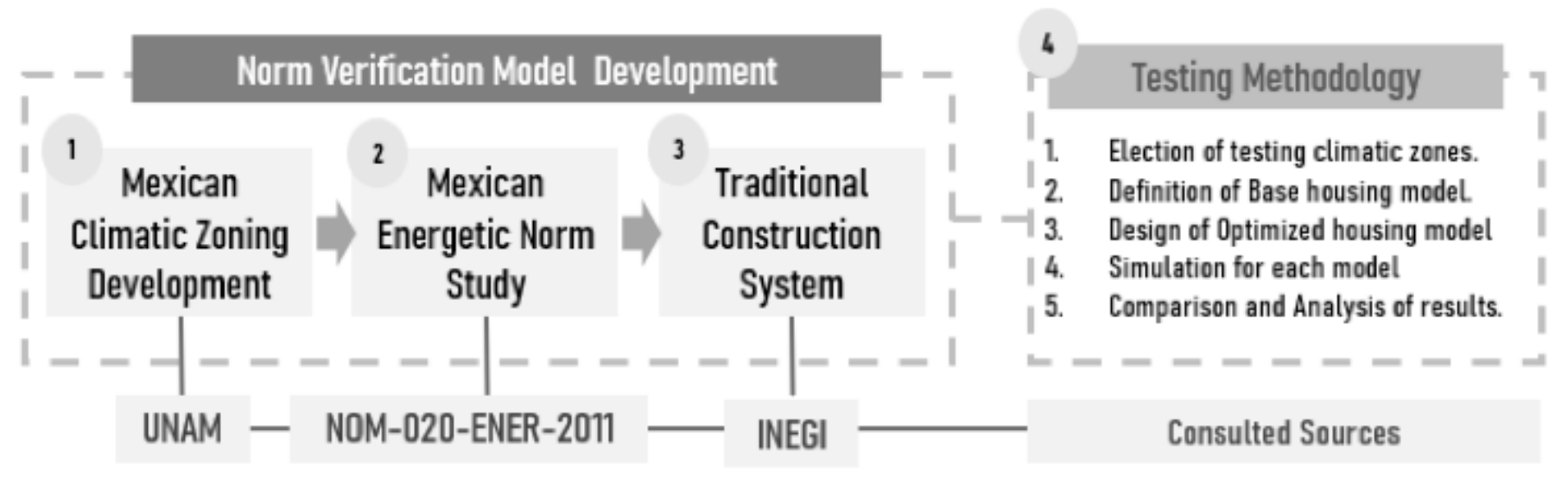

Figure 1. A general scheme of the four research stages for the energy verification model.

\subsection{Climatic Zoning Development}

Weather files are an important element for energy simulation because of their influence on the building energy performance results. The article entitled Impact Assessment of Building Energy Models Using Observed vs. Third-Party Weather Data Sets clarified that: "The sensitivity analysis of the main weather parameters showed the different influence that each parameter had on the energy demand variation of each test site". In this regard, the relative humidity and wind direction had little influence on the models; the two parameters with the strongest influence on the models were wind speed and temperature [14]. The variations in elemental climatic characteristics result in different thermal envelope behaviors. Then, the importance of having a classification of different climatic zones, with their corresponding weather reference values, becomes a reason for considering climatic zoning. There are some examples of how weather conditions and climate affect the thermal envelope and HVAC system performance. Hang et al. explained the importance of considering weather statistics for improving the energy performance of HVAC systems. They tested an HVAC system control with the new set-point temperatures calculated from the derived equation, improving thermal comfort by $38.5 \%$. This study confirmed that a cooling set-point temperature that considers both the thermal characteristics of a building and the weather conditions effectively enhances the indoor thermal comfort during summer. They also noted the need for a continuous update of the existing hourly weather data files that are used in dynamic simulations or for the prediction of the peak thermal loads of buildings, as they affect the capacity of HVAC equipment to respond to current climate change $[15,16]$.

Why does climatic zoning need to be developed for Mexico? The only available zoning was developed by the Institute of Geography of the Mexican Autonomous University (UNAM) in 2005. In the introduction, we explained how they delimited the zones. To delimit the domains with potentially similar climates, a regionalization was proposed based on the country's orography, hydrology, and elevation. Figure 2, for example, explains the relationship between cities elevation and their climatic characteristics (higher elevations are associated with cold weather, and lower elevations with warm weather). The geographical characteristics of rainfall, humidity, and temperature change even between short distances. As a consequence, a wide diversity of climates is created [17]. This zoning classifies the national territory into eleven zones. Each of these zones was determined by the study of several factors: dominant winds, rainfall patterns, annual temperature records, thermal annual oscillations, relative humidity, and average temperature rates. There are similarities between different climatic zones. For example, the states located on the coast line of the Pacific Ocean (Guerrero, Jalisco, Michoacán, and Oaxaca) present iso-thermal climates, meaning they have a thermal oscillation of $5{ }^{\circ} \mathrm{C}$ or less throughout the year.

The impact of climate change and warming on the climatic characteristics of Mexico must be highlighted. Liberman and O'Brien explained how climate change produces varia- 
tions in moisture, rainfall, and mean temperatures. By analyzing the regional impacts of global warming in the country, the results always tend to be warmer and drier. Whichever model is used, it seems that potential evaporation will increase, and, in most cases, moisture availability will decrease, even where the models project an increase in precipitation. Owing to the effects of global warming, the temperature, moisture and humidity data have variances over time [18]. From this statement, weather data and climatic files are necessary for obtaining more accurate energy simulations.

\section{CAPITAL CITIES ELEVATION COMPARISON}

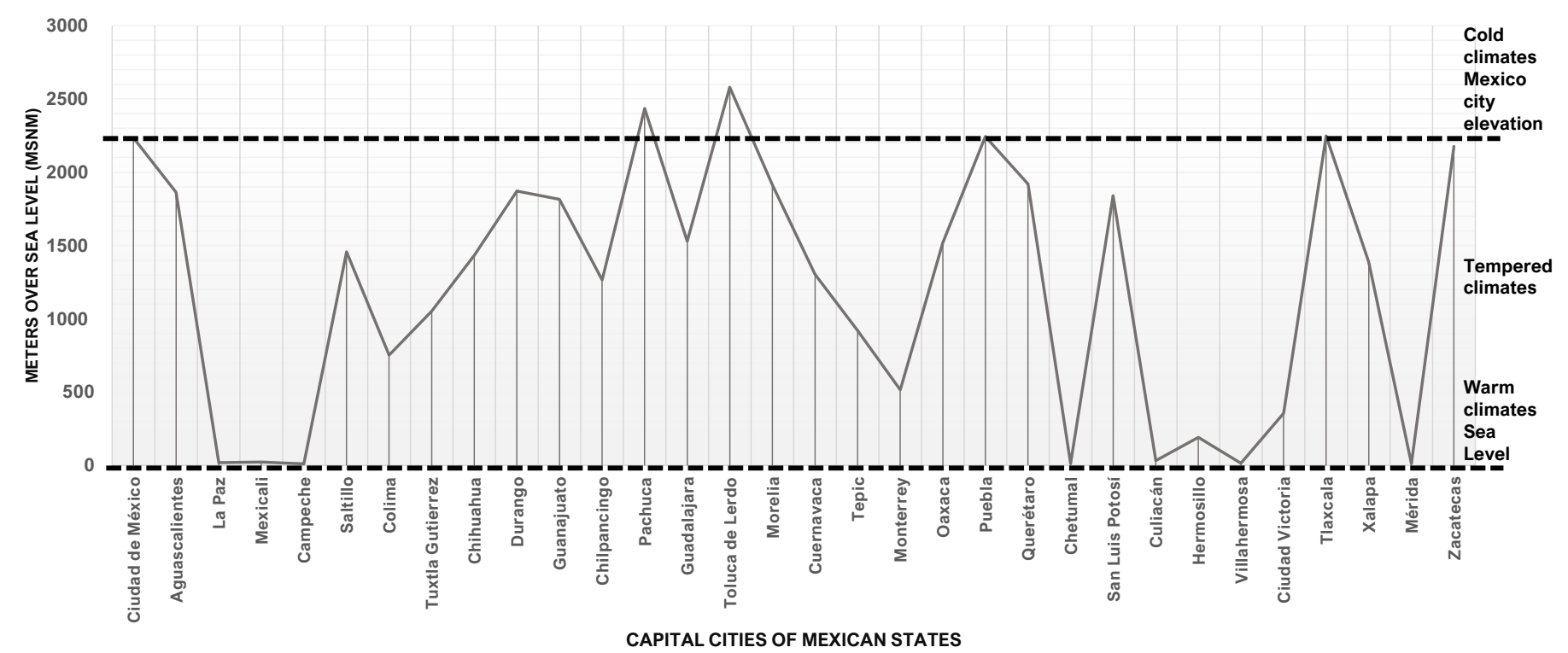

Figure 2. Comparison of Mexican capital cities elevations, and the relationship of elevation with cold and warm climates. The coldest climates are located on mountains and at high elevations, whereas the warmest climates are located at low elevations close to sea level.

For constructing a building energy model (BEM) and a verification/certification model, a simplified and more practical climatic zoning is needed. A similar climatic zoning design procedure was followed by Bai and Wang for defining climatic zoning in China. They used building simulation to analyze the potential impact of re-assignment of cities to new thermal climate zones based on public building energy consumption and recent meteorological data..The defects of current climate zones were identified and new updated zones were defined [19]. For each climatic zone, several reference and nominal values were considered for their entry in the software calculations (average temperatures, average humidity, winter and summer severity, etc.) Therefore, we decided to design a new zoning based on thermal demands. For the proposed classification, several housing models that are common in the majority of Mexican cities were studied. Three models were selected: economic house, medium-level house, and apartment block. The three models were selected from the web-page catalogue of a real estate broker affiliated with INFONAVIT [20]. These models were chosen because of their constant replications in all the Mexican states. For the energy simulation, Open Studio software with the extension SGSAVE was used. SGSAVE is a complement developed by the Spanish energy testing software developer EFINOVATIC [21]. Since 2018, it has served as an official verification tool of the energy requirements of the Spanish building normative. Using the Energy Plus simulation engine (with local parameters and building geometry), the software conducts an energy simulation, providing an analytic report of different environmental results [22].

Using this software, the project continued with simulations for each house model. The simulation output the energy demands for heating and cooling for each housing type (expressed in $\mathrm{kWh} / \mathrm{m}^{2}$ ). The simulation period considered for the results was one year. 
The Energy Plus Weather File (EPW) file or weather data file of capital cities [23] was used of each of the 32 states of the country, including the nation's capital city (Mexico City). Different simulations were performed by changing the position of the principal façade oriented to the four cardinal points (north, south, east, and west) for each house type. For a new simulation, we also considered the use of three different window-to-wall ratios: $10 \%$, $30 \%$, and $60 \%$ of openings (Figure 3 ).

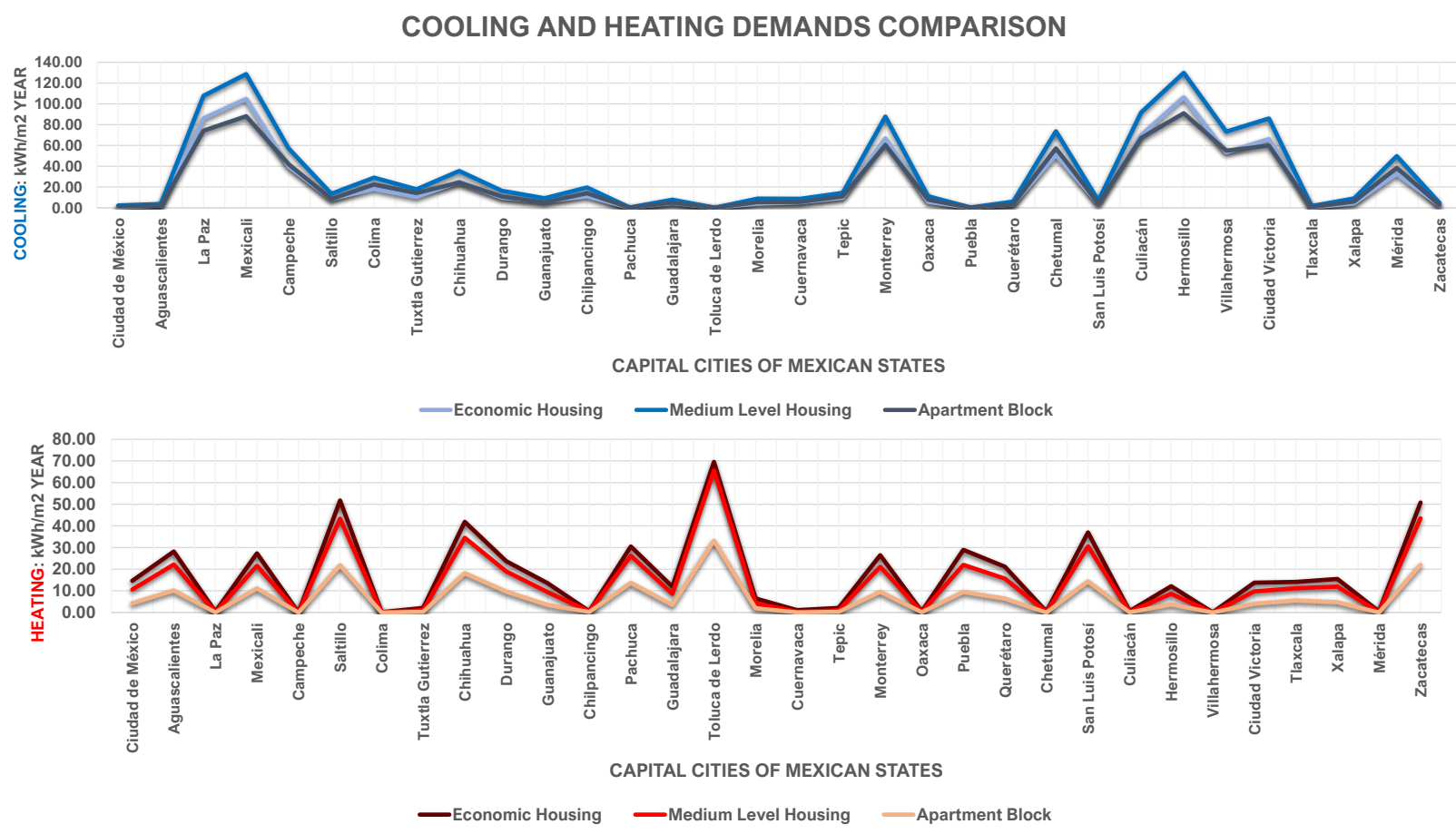

Figure 3. Cooling and heating comparison for each of the housing model types, showing that medium-level housing registered the highest cooling demands in all climates. Economic houses registered the highest heating demands; however, scaling the results, the heating demands are lower $\left(70 \mathrm{kWh} / \mathrm{m}^{2}\right.$ for the highest value) than the cooling demands $\left(125 \mathrm{kWh} / \mathrm{m}^{2}\right.$ for the highest value).

Adding all the procedures, 384 simulations were conducted for both the heating and cooling demands for each house type. Once all the energy demand results were compiled, the four possible orientations were averaged for each capital city and each house type. The next step was averaging all the energy demands for all the capital cities, obtaining a mean value for heating demand and other for cooling demand. For the last step, an average value of all the energy demand for the three housing types was generated, obtaining final energy demand values for each capital city. The next step was attaining normalized values by scaling all cities' values for the collection of a unique scale of comparable values. We normalized the values by calculating an average value from all cities' values. This global mean value was assigned a numeric value of 1 . So all cities' values were scaled in comparison with this numeric value. This procedure resulted in a scale ranging from 1 to 3 for three winter severities and a from $\mathrm{V}$ to $\mathrm{Z}$ for five summer severities. The final scale included a total of ten climatic zones, displayed on Figure 4 map.

The ten climatic zones were divided in three groups. The first group corresponds to cold and temperate climates, containing V1, V2, and V3 zones. The V zones contain the majority of the national territory, except for Estado de Mexico, which has the coldest climatic conditions in the country. This group has a temperature range of 0 to $21{ }^{\circ} \mathrm{C} 73 \%$ of the time [24]. The next group corresponds to warm and tropical climates, containing W1, W2, and X1 zones. The W and X zones are located in states next to the Pacific Ocean (Michoacán and Colima), and Yucatan Peninsula. This group presents a temperature range from 21 to $27{ }^{\circ} \mathrm{C} 40 \%$ of the time, and from 27 to $38{ }^{\circ} \mathrm{C}$ the other $40 \%$ of the time [24]. 
The last group corresponds to arid and desert climates, containing Y1, Y2, Z1, and Z2 zones. The $Y$ zones are located in the northern coastal states (Baja California Sur, Baja California Norte, Sinaloa and Tamaulipas, and Sonora) and Nuevo León. This group presents a temperature range from 27 to $38^{\circ} \mathrm{C} 50 \%$ of the time, and temperatures higher than $39^{\circ} \mathrm{C}$ the $10-20 \%$ of the time [24].

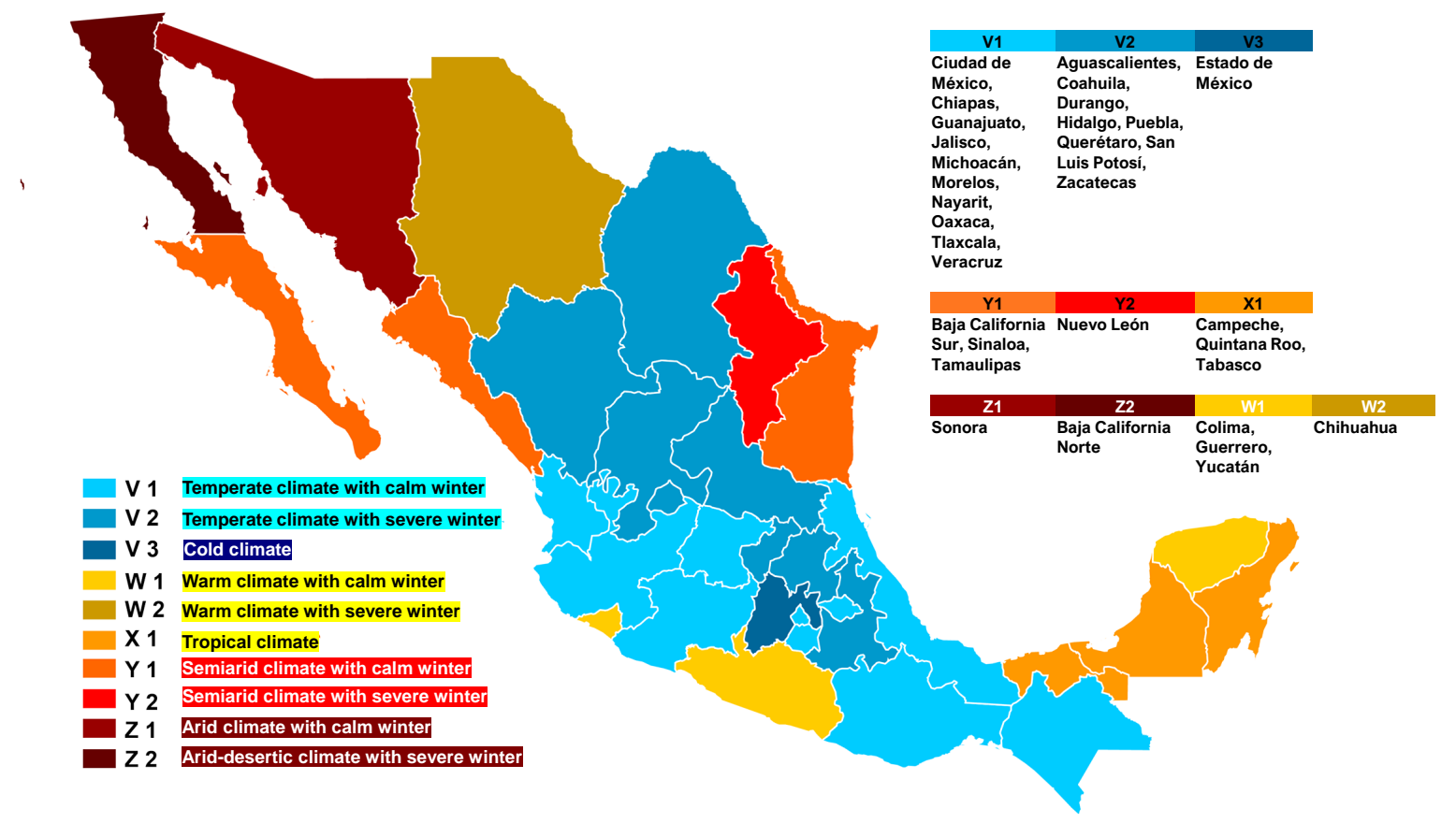

Figure 4. Climatic zoning designed for the proposed verification method using winter and summer severities for analysis and comparison.

\subsection{Study of Mexican Energy Standard}

For the second aim of the methodology, we conducted an extensive search and review of the existing Mexican energy standard. Notably, there is no mandatory energy standard in Mexico. This situation is common for North America. In the United States, for example, some states have regional regulations that include an energy performance test. Others states only incorporate energy strategies in their own construction codes. The American energy codes rely on ASHRAE guidelines and reference values. In Mexico, there are some energy guidelines and a group of non-mandatory standards [25]. For this project, we used NOM-020-ENER-2011, published by the National Committee for the Efficient Use of Energy (CONUEE) [3]. With voluntary application, this norm uses the comparison of energy savings for a normal case and a saving-based case as its principal verification method (designed by the optimization of the thermal envelope of buildings and the heat gains analysis). The verification calculation begins with the definition of a reference model for the building using reference values (provided by attached tables and an application manual contained in the standard's documentation). The next step is the calculation of the same variables, but from the projected model for the building. This information is obtained by analyzing the building geometry and consulting the available data on the plans and material catalogue for the project [7].

With this previous information, the calculations provided by the standard provide the heat gains by radiation and conduction for the reference and projected models. If the heat gains obtained by the projected model are equal to or less than the heat gains of the reference model, then the building complies with the standards. Therefore, the standard focuses on the verification results only in terms of the performance of the thermal envelope, neglecting other results obtainable from a simulation. A verification standard is not an energy performance study. The use of elements, like internal gains, occupation calendars, 
and energy expenses of electricity and sanitary hot water, is difficult to implement in a standard because they are dependent ob the user. The Spanish Building Technical Code (CTE) does not consider them, either.

In this proposed model, the HVAC performance is important. The inclusion of HVAC design and performance in building energy performance for an energy certification is complex. HVAC design requires a specific study of demands and an input of actual user variables, like occupancy, space use, and schedules. The HVAC equipment design is also dependent the unique characteristics of the project, for which it is difficult to determine an exact result for a final energy certification for standard verification. Due to the functionality of the Mexican verification (applicable for preliminary architectural projects), the project can be simulated with ideal loads for HVAC equipment, because the standard work with heat gains, not energy demands. The simulation tools available on the market, like Energy Plus, can simulate and describe energy demands by defining certain HVAC equipment characteristics, but the customization options result in a large number of possible results. The simulator requires the collaboration with an expert in HVAC installations and sizing. The simulation parameters increase in complexity as the HVAC design evolves and requires more precise information. This is complicated because it implies a level of updating, which will increase the cost. It is recommended to first verify if a project complies with the standard and then perform a personalized energy simulation of the particular building project.

In summary, the principal focus of the NOM-020-ENER-2011 is the heat transfer control of the thermal envelope for improving energy demands. Instead of optimizing or pursuing the goal of a Nearly Zero Energy Building (like recent energy codes and certification models), the Mexican standard focuses on improving energy demands for cooling systems due to the prevalence of arid, warm, and humid climatic zones in the country. The principal energy consumption rates for thermal conditioning is due to cooling (40\%) [11], The standard requires low improvement levels for maintaining low construction costs and the competitive housing affordability for most of the Mexican population. Nine of ten Mexican citizens are planning to acquire a house, but $45 \%$ of them cannot afford it [26]. The standard establishes several reference coefficients for calculating the energy efficiency: U-values, temperatures, glazing coefficient, etc. (Figure 5). However, as the scope of the standard is thermal envelope performance for heat transfer, it ignores thermal comfort considerations. This means that the the standard does not provide a comfort model for simulation, following only its own calculation method.

\begin{tabular}{|c|c|c|c|c|c|c|c|c|c|c|c|c|c|c|c|c|c|c|c|c|c|c|}
\hline & \multirow{5}{*}{ Ciudad } & \multicolumn{15}{|c|}{ CONDUCCIÓN } & \multirow{2}{*}{\multicolumn{5}{|c|}{$\begin{array}{c}\text { RADIACIÓN } \\
\text { Transparente }\end{array}$}} & \multirow{5}{*}{$\begin{array}{l}\text { Barrera } \\
\text { para } \\
\text { vapor }\end{array}$} \\
\hline \multirow{4}{*}{ Estado } & & & & & & Opac & & & & & & & Transp & parent & & & & & & & & \\
\hline & & \multirow{3}{*}{\begin{tabular}{|c|} 
Temp. \\
Interior
\end{tabular}} & \multirow{3}{*}{$\begin{array}{c}\text { Superficie } \\
\text { Interior }\end{array}$} & & Tempe & peratu & ura e & quivo & alente & prom & nedio Te & $\left({ }^{\circ} \mathrm{C}\right)$ & & & & & & & & & & \\
\hline & & & & \multirow{2}{*}{ Techo } & \multicolumn{4}{|c|}{ Muro Masivo } & \multicolumn{3}{|c|}{ Muro Ligero } & \multirow{2}{*}{$\begin{array}{l}\text { Tragaluz } \\
\text { y domo }\end{array}$} & \multicolumn{4}{|c|}{ Ventanas } & \multicolumn{5}{|c|}{$\begin{array}{l}\text { Factor Ganancia Solar } \\
\text { Promedio FG }(\omega / \mathrm{m} 2)\end{array}$} & \\
\hline & & & & & Norte & Este & Sur & Oeste & Norte & Este $\mathrm{S}$ & Sur Oeste & & Norte & Este & Sur & Oeste & $\begin{array}{c}\text { Tragaluz y } \\
\text { domo }\end{array}$ & Norte & Este & Sur & Oeste & \\
\hline Aguascalientes & Aguascalientes & 24 & 26 & 37 & 24 & 27 & 26 & 25 & 30 & 333 & $32 \quad 32$ & 22 & 23 & 24 & 24 & 24 & 274 & 91 & 137 & 118 & 146 & \\
\hline Baja California Sur & La Paz & 25 & 31 & 45 & 31 & 34 & 32 & 33 & 36 & 403 & $38 \quad 39$ & 26 & 27 & 28 & 29 & 29 & 322 & 70 & 159 & 131 & 164 & $\mathrm{Si}$ \\
\hline \multirow[t]{2}{*}{ Baja California Norte } & Mexicali & 25 & 34 & 50 & 36 & 40 & 37 & 38 & 41 & 45 & $43 \quad 45$ & 29 & 30 & 32 & 32 & 32 & 322 & 70 & 159 & 131 & 164 & \\
\hline & Ensenada & 24 & 25 & 35 & 22 & 25 & 24 & 23 & 28 & 313 & $30 \quad 30$ & 20 & 22 & 22 & 22 & 23 & 322 & 70 & 159 & 131 & 164 & $\mathrm{Si}$ \\
\hline Campeche & Campeche & 25 & 31 & 45 & 31 & 35 & 33 & 33 & 36 & 403 & $38 \quad 40$ & 26 & 27 & 29 & 29 & 29 & 284 & 95 & 152 & 119 & 133 & $\mathrm{Si}$ \\
\hline \multirow[t]{2}{*}{ Coahuila } & Saltillo & 25 & 27 & 38 & 25 & 28 & 26 & 26 & 30 & 343 & $33 \quad 33$ & 22 & 24 & 24 & 24 & 25 & 322 & 70 & 159 & 131 & 164 & \\
\hline & Torreón & 25 & 30 & 43 & 30 & 33 & 31 & 31 & 35 & 393 & $37 \quad 38$ & 25 & 27 & 28 & 28 & 28 & 322 & 70 & 159 & 131 & 164 & \\
\hline Colima & Colima & 25 & 29 & 42 & 28 & 32 & 30 & 30 & 34 & 383 & $36 \quad 37$ & 24 & 26 & 27 & 27 & 27 & 274 & 91 & 137 & 118 & 146 & $\mathrm{Si}$ \\
\hline \multirow[t]{3}{*}{ Chiapas } & Tuxtla Gutiérrez & 25 & 29 & 42 & 29 & 32 & 30 & 30 & 34 & 383 & $36 \quad 37$ & 24 & 26 & 27 & 27 & 27 & 272 & 102 & 140 & 114 & 134 & $\mathrm{Si}$ \\
\hline & $\begin{array}{c}\text { San Cristóbal de } \\
\text { las Casas }\end{array}$ & 23 & 22 & 31 & 19 & 20 & 20 & 20 & 25 & 27 & $27 \quad 26$ & 18 & 20 & 20 & 20 & 20 & 272 & 102 & 140 & 114 & 134 & \\
\hline & Arriaga & 25 & 31 & 46 & 32 & 35 & 33 & 33 & 37 & 413 & $39 \quad 40$ & 26 & 28 & 292 & 29 & 29 & 272 & 102 & 140 & 114 & 134 & $\mathrm{Si}$ \\
\hline Chihuahua & Chihuahua & 25 & 28 & 41 & 27 & 30 & 29 & 29 & 33 & 363 & $35 \quad 36$ & 24 & 25 & 26 & 26 & 26 & 322 & 70 & 159 & 131 & 164 & \\
\hline \multicolumn{2}{|c|}{ Ciudad de México } & 23 & 23 & 33 & 20 & 22 & 22 & 21 & 26 & 292 & $28 \quad 28$ & 19 & 21 & 21 & 21 & 21 & 272 & 102 & 140 & 114 & 134 & \\
\hline
\end{tabular}

Figure 5. Example table of the reference values quoted in NOM-020-ENER-2011. It contains interior and exterior temperatures, U-values, and other coefficients. 


\subsection{Traditional Construction Systems}

For the third aim of the methodology, we researched the main traditional construction systems in Mexico. This included official information sources, like the Home Survey of the National Geography and Statistics Institute (INEGI) [27], and two scholarly publications about construction systems used in Latin American countries [8,28]. Each year, INEGI publishes the results obtained from an annual population census. Among the different result categories listed, one is focused on housing. The systems listed on the report were studied, and we compiled a list of those most used in the country. The listed systems were divided by the building elements to which they are applied (roof, walls, or ground), and the principal material present in their component elements.

As shown in Figure 6, the principal materials used in Mexican traditional construction systems were determined. For the construction of ceilings, the principal material used is concrete slab or joist and beams slab, with a $70 \%$ incidence. The second most popular material for ceilings is metallic sheet with a $16 \%$ incidence, followed by wood at $4 \%$ [27]. For the construction of floors, the principal material used is concrete slab, at $55 \%$ incidence, followed by covering (wood and mosaic) at 53\% and pure soil at 3\% [27]. For the construction of walls, the principal material used is fabrics (brick, block, stone, and partition) at an $85 \%$ incidence, followed by adobe (vernacular technique with mud and straw) at $9 \%$ and wood at $5 \%$ [27]. The survey results showed that the main construction system used in Mexican buildings is reinforced concrete with an incidence between 55\% and 85\% for all components). Mexican constructors used local vernacular techniques inherited by their ancestors, like adobe and bahareque (construction technique that uses adobe, straw, bamboo, and metal or fiber cement sheets for walls).

\section{CEILING MATERIALS - Housing} Survey 2018

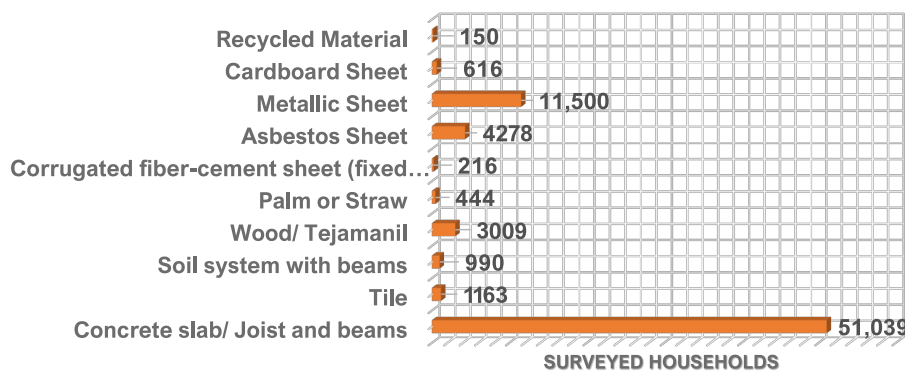

FLOOR MATERIALS - Housing Survey 2018

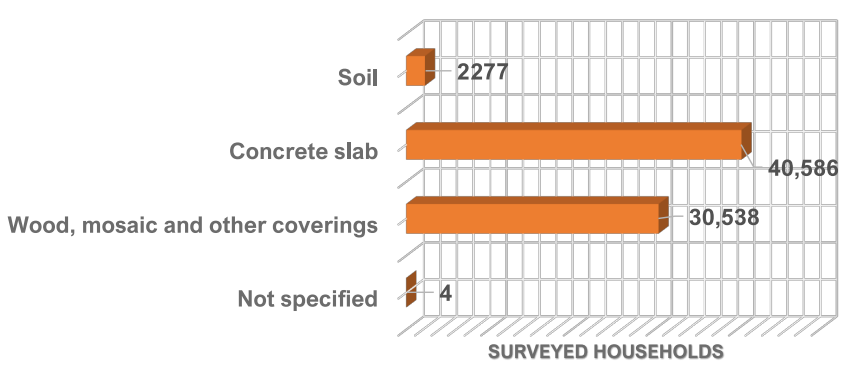

WALL MATERIALS - Housing Survey 2018

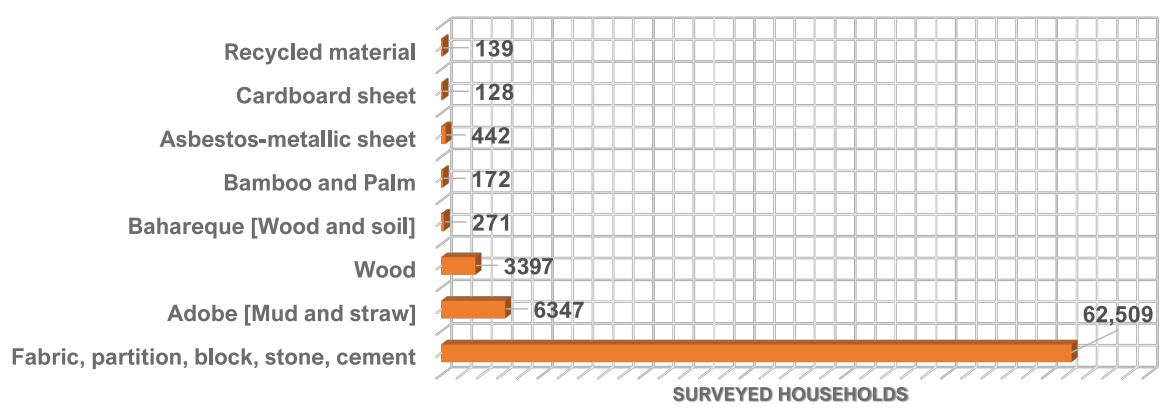

Figure 6. The principal materials used in Mexican housing grouped by building components (walls, ceiling, and floor). A total of 73,405 houses were considered by the National Survey of Housing and Population, National Institute of Statistics and Geography (INEGI) 2018.

By analyzing the results, two undesirable practices were denoted. First is the use of fiber-cement in construction. This material contains asbestos. Constant asbestos exposure poses serious human health risks for diseases, like lung cancer, asbestosis, and mesothe- 
lioma. It is not dangerous when packed or sealed in elements, like tiles, panels, or cabinet tops, but they are hazardous when those elements are in bad condition and the interior material is not sealed (resulting in the release of asbestos fiber in the air). Asbestos is forbidden in the majority of world construction standards due to its dangerous effects [29]. Knowing its hazardous characteristics, the common use of fiber-cement materials in Mexican housing is unsafe. Notably, many houses do not have floors, using the local soil (3\%). In Mexico, almost 14 million houses do not meet the minimum acceptable conditions for a comfortable house due to the dirt floor and lack of access to quality water supply and sanitation services. In Mexico, 2 of 10 citizens lack access to one public service in their homes [30]. This is an opportunity for improving social housing conditions; improving energy performance and internal comfort with affordable materials could contribute to this improvement.

From each of the construction systems, we broke down the component elements, listing the different material layers' compositions. Finally, the four main characteristics of every material listed in the catalogue (layer width, conductivity coefficient, density, and measure unit) were researched and reported. With all the data compiled, the final construction system catalogue was completed.

\subsection{Testing Methodology}

For the fourth aim of the methodology, the testing of the proposed verification model of the Mexican standard, we followed two fundamental steps. First, we needed to learn and understand the digital software SGSAVE provided by EFINOVATIC [21]. Next, we designed a personalized testing methodology for the verification of the model to achieve the desired results. The digital tool used for the testing methodology was the energy simulation software Open Studio, using the complementary software called SGSAVE.

For understating how SGSAVE works, we reviewed the energy performance simulation process in Open Studio [31]. Open Studio is software contained inside the Google Sketch-up interface. The energy simulation process is composed of four principal phases: modeling, definition, simulation, and reporting. For the first phase, the 3D modeling of the evaluated building project, the user works in the Google Sketch-up interface. In this phase, the user establishes the physical values of the building (height, length, width, opening geometry, etc.). For the second phase, the user establishes the parameters and reference values for the modeled building project (materials, construction systems, schedules and calendars, HVAC definitions, space types, etc.). For the third phase, the user defines the simulation parameters before running the simulation engine (run period, desired report results, etc.). The final phase is the report, where the user analyzes the generated simulation report with the corresponding results (verification of the standard, energy demands, etc.). Open Studio functions are delimited from the first to the last phase.

SGSAVE is software that offers a direct verification of the Spanish energy standard and generates a complete report of all energy simulation results, including the European Union energy label designed by the EU Directive 92/75/EC [32]. SGSAVE introduces the reference values, parameters, and directives of Spanish energy standards (CTE) into Open Studio interface by: (1) entering Spanish/European reference values and parameters and (2) generating the Spanish/European verification certification report of compliance. The parameters and reference values are introduced by the user using a SGSAVE tool panel in the Google Sketch-up interface. With this panel, the user can introduce values, like thermal bridges, U-value limit verification, thermal space configuration for reference occupation schedules, window and door configurations, etc. It also includes tools to clean and refine the three-dimensional model, HVAC installation design, and location customization tools. For the report final phase, SGSAVE generates a certification report that declares whether the building project complies with the standard. The report also includes a graphic of detail heat gains, projected energy demands for ideal loads, and physical characteristics of the model (square meters per thermal zone, for example). Figure 7 describes the workflow. 


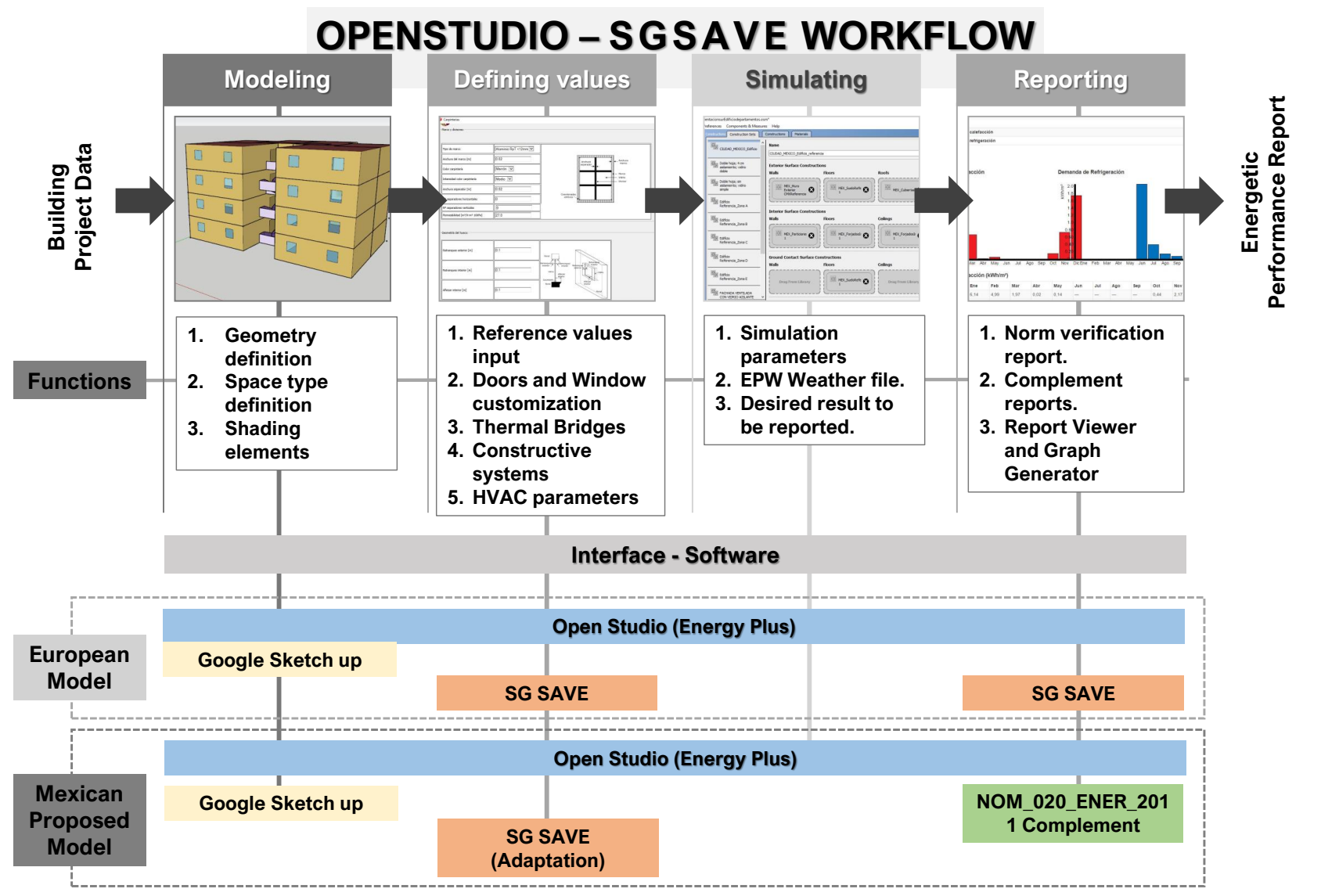

Figure 7. Open Studio and SGSAVE workflow diagram explaining the work process for entering the building project in the software interface and using the digital model for energy simulation.

By understanding how SGSAVE works in refining and adapting the European/Spanish standard requirements for Open Studio parameters, our aim was to adapt the software for the Mexican standard. As the standard's development in Mexican is in its infancy, the technical data were insufficient for fulfilling all SGSAVE data requirements. For the testing exercise, the data provided by the Mexican standard was used, and the Spanish/European values were used for the remaining fields to enable testing the Mexican data's adaptability to the software.

For each component (roof, openings, walls, doors, and shading elements), the software allows the user to assign values, entering the data corresponding to each requested variable, and then the user assigns a construction system for each element. Each construction system was entered into the software, determining the width of each of its composition layers and their respective conductivity coefficients and characteristics, like density and measurement unit. For the last arrangements of the thermal envelope's geometrical model, the user enters the remaining data needed, like occupation calendar, zone uses (kitchen or bedroom, for example), external shading components, and immediate context elements (trees, roads, location, or other adjacent buildings) [31]. A base model was introduced and configured with Openstudio tools, following the geometry of a typical social housing model, replicated on different Mexican cities (Figure 8). 


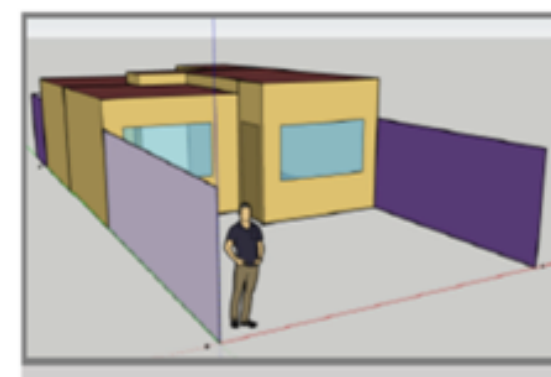

South Facade
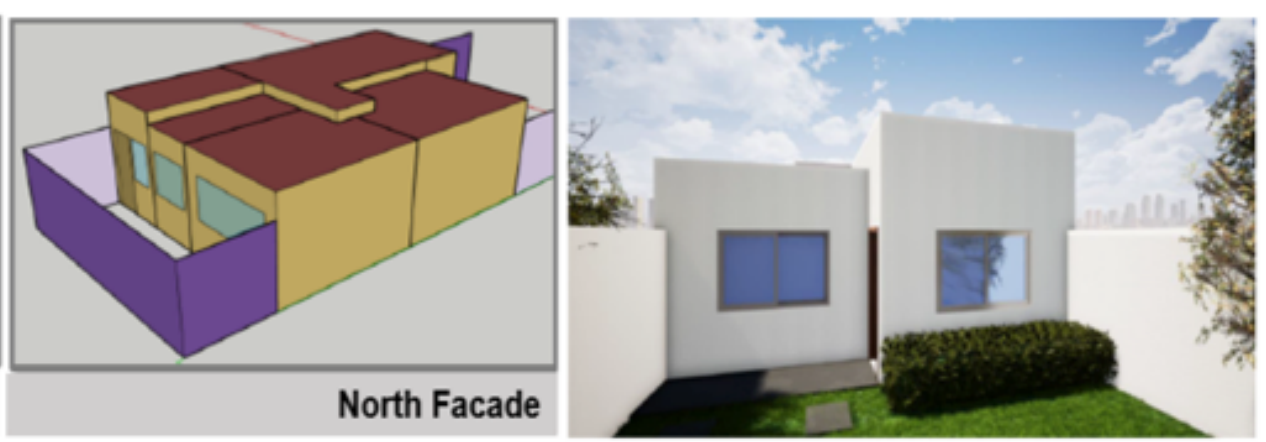

Figure 8. The basic model of the economic housing type. Geometry modeled in the Open Studio interface.

Before launching the simulation, the user must enter the weather file EPW of the city's project location and choose the desired simulation period. For the next step in the fourth aim, we determined the application of the following testing methodology. First, the most representative climatic cities of Mexico were chosen in accordance with summer severities (V, W, X, Y, and Z, returning to Figure 4) and those with the most extreme weather: Toluca de Lerdo for the coolest city and Mexicali for the warmest city. In the next step, the housing models were used and different simulations were performed by changing the weather file. Before running simulation processes for the testing method, a Building Component Library (BCL) report-generation add-on for Mexican standard verification was installed in the software. This add-on was developed by the Mexican agency ITÖM. It is a public-access complement provided at no cost. The add-on takes the geometry and the simulation parameters of the tested model and generates a report with the verdict (if the project complies with the standards) [33].

Using the verification complement of NOM-020-ENER-2011 for Open Studio, we tested if the building complied with the standards. If not, changes and bio-climatic design strategies for the optimization of the economic housing thermal envelope were applied to increase the energy savings (improving the score) of each housing model. After verifying the improved models for economic housing with personalized content for each tested climatic zone, new simulations were run for the improved models to verify if the model complied with the norm standards. With the analysis of the results of radiative and conductive heat gains, we compared the simulated energy savings between the normal case and the improved case. Finally, new simulations were run, but with the Open Studio report manager, for evaluating the differences between both reports.

Although these test simulations provided results for improving building energy performance, remember that the simulation needed other factors that are strictly related to the potential user. David Bienvenido Huertas stated: "Energy consumption simulations are directly related to six factors: three technical and physical factors (climate, building envelope, and building equipment) and three social factors (operation and maintenance, occupant behavior, and indoor environment conditions). So, the energy performance of a building depends not just on technical characteristics (e.g., the thermal performance of the facade) but also on users' behavior" [34]. For the simulation, the Mexican user operation, occupant behavior, and indoor environment conditions characteristics were needed. Some information was provided by NOM-020-ENER-2011 guide, but, for the remaining variables, the CTE (Spanish Building Technical Code) calendars and reference values [35] provided by SGSAVE were used. The reference values used from CTE were: occupation calendars, thermal bridges, average consumption rates, etc. The simulations were run with an HVAC configuration for ideal loads.

\subsection{Testing Application}

After reviewing the steps followed for the testing of the verification model, the climates and model characteristics were explained. For the test, six different climatic zones were chosen. For the cold-climate group, V3 and V1 zones were chosen. V3 has the coldest 
climatic conditions, with Toluca de Lerdo as the studied city. We selected V1 because it represents the temperate climatic conditions, with Mexico City as the studied city. For the warm-tropical group, W1 and X1 were chosen: W1 because it represents warm climatic conditions, with Merida as the studied city, and X1 because it represents the tropical climatic conditions of Yucatan Peninsula, with Campeche as the studied city. Finally, for the arid desert group, zones $\mathrm{Y} 1$ and $\mathrm{Z} 2$ were chosen: $\mathrm{Y} 1$ because it represents the semiarid climatic conditions of he northern states, with Culiacan as the studied city, and Z2 because it has the warmest climatic conditions, with Mexicali as the studied city.

\subsubsection{Basic Model: Definition and Test}

Recalling the information provided in the Introduction, INFONAVIT is the organization that manages social housing for workers. As portrayed in its official housing catalogue, they used to build the same housing model in different cities and states due to having the most economic design and construction [20]. The principal aim of our project was applying the Mexican standard to social housing, so the first step in the testing stage is the definition of a universal basic model, using the analogous example from the INFONAVIT housing catalogue. This model is the most replicated and affordable house in the catalogue.

The construction system used for the basic model was a reinforced concrete structure, with brick walls with plaster $(17 \mathrm{~cm}$ wide). The floor was a $30 \mathrm{~cm}$ foundation bed/slab, and the ceiling was a joist and block concrete slab. After designating the tested climatic cities for the testing exercise, the base model was simulated for each of the EPW weather files (corresponding to each city). The add-on for Open Studio was run, and the model compliance with NOM-020-ENER-2011 was tested. None of the climatic zone models complied with the standard because all resulted in a negative energy savings of $-151 \%$. In other words, if the reference model had an allowed heat gain limit of 1519 Watts for thermal envelope, the base model had a calculated heat gain of 3816 Watts for thermal envelope. It exceeds the limit almost 150\%. These results showed the unsuitability of using the same housing model for all cities without considering the climatic characteristics.

\subsubsection{Improved Model: Definition and Test}

Gumbarevic explained that the main goal of model improvement, is to minimize the heat transfer through the building envelope. For that reason, it is important to pay attention to the design and construction details in all delivery phases-from schematic and design phases up to the construction phase [36]. Because of the poor results obtained with the basic model simulations, the next step was the implementation of bioclimatic strategies for each climatic zone. For choosing the correct bio-climatic strategies, we used weather analysis software Climate Consultant V6 [24]. Using the ASHRAE 55 model for defining thermal comfort parameters, Climate Consultant software generated Givoni's diagrams for describing the most adjustable bio-climatic strategies for each climate (Figure 9); with the base construction systems, several changes were implemented to construct an improved model that should comply with the Mexican energy standard.(A graphic display of implemented strategies is showed on Figure 10)

For the V3 improved model, a continuous thermal insulation layer was proposed, using expanded polystyrene (EPS) with a thermal conductivity of $0.029 \mathrm{~W} / \mathrm{m}^{2} \mathrm{~K}$, and a width of $6 \mathrm{~cm}$. By using insulation, the thermal masses of the brick and concrete elements were enhanced. Several shading elements were added to the windows. For the improved V1 model, the implemented changes were: a continuous thermal insulation layer using expanded polystyrene (EPS) with a thermal conductivity of $0.029 \mathrm{~W} / \mathrm{m}^{2} \mathrm{~K}$ and a width of $3 \mathrm{~cm}$; by using the insulation, the thermal mass of the brick and concrete elements retained heat gains for nocturne diffusion; horizontal shading elements on the south façade for sun heat control; shading elements for windows; and openings for sun heat control. 

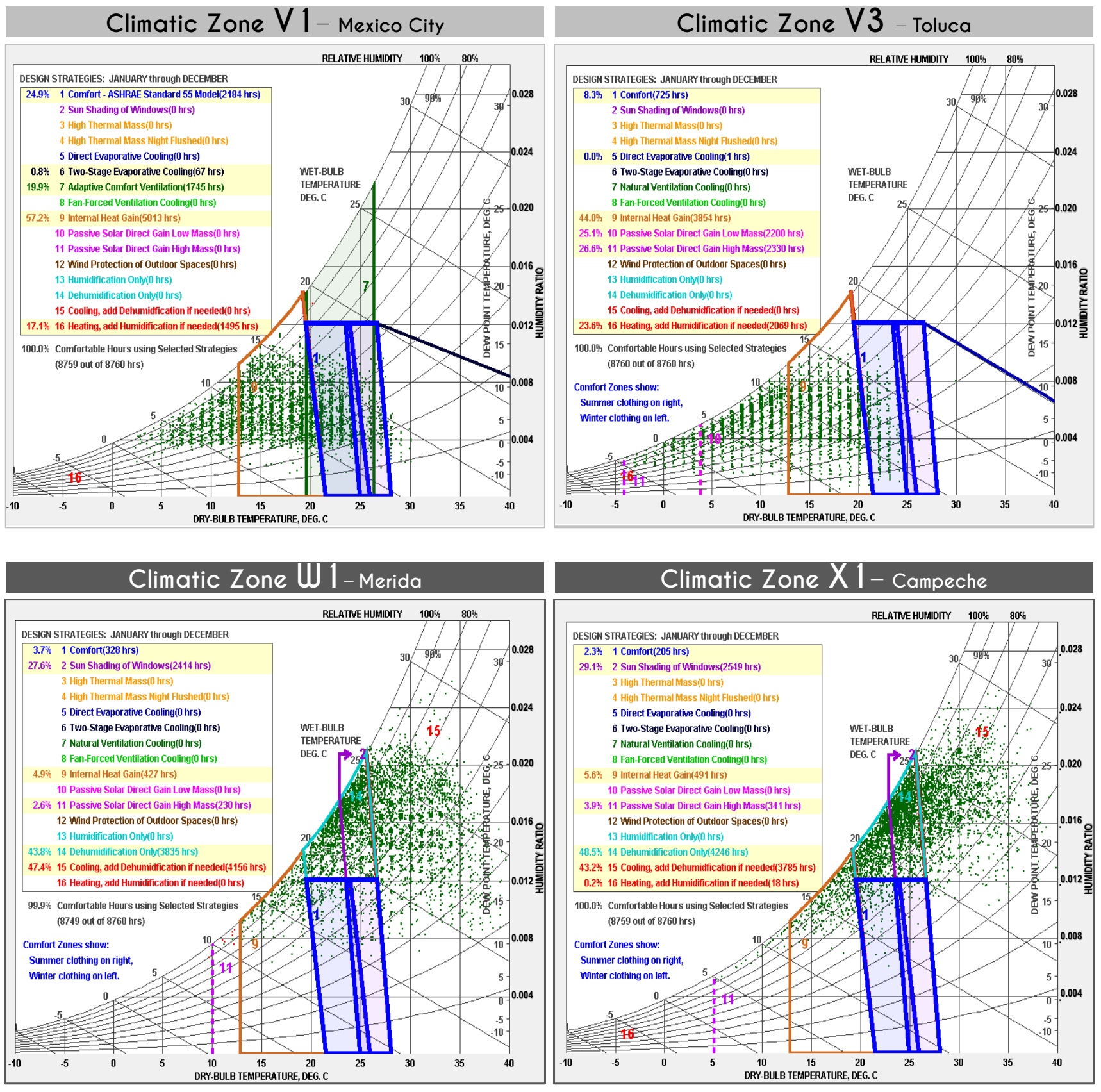

Figure 9. Cont. 

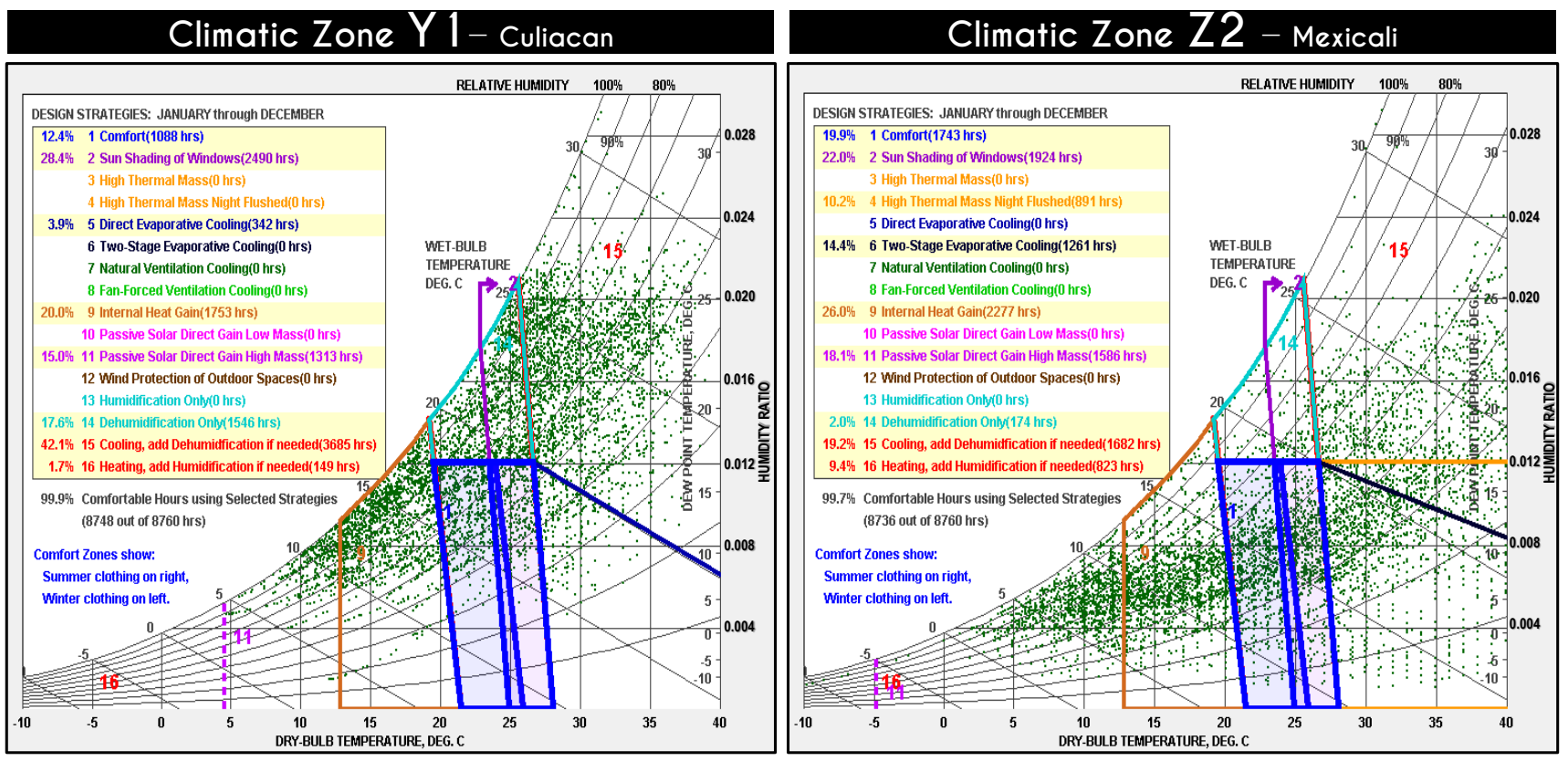

Figure 9. Givoni's diagrams produced by Climate Consultant V6 software [24]. Each diagram describes the suggested bio-climatic strategies for reaching thermal comfort inside the improved models for each climatic zone.

For the improved W1 model, the construction system of the ceiling was changed from the previous joist and block concrete slab to a lightweight EPS-blocks concrete slab for thermal insulation. In addition, a continuous thermal insulation layer was proposed using EPS expanded polystyrene with a thermal conductivity of $0.029 \mathrm{~W} / \mathrm{m}^{2} \mathrm{~K}$ and a width of $3 \mathrm{~cm}$. Using the insulation, the thermal masses of the brick and concrete elements were enhanced. The walls were modified, adding an extra layer of brick with a $3 \mathrm{~cm}$ air gap between them. For better ventilation flow inside the building, $30 \mathrm{~cm}$ was added to the interior height. The façade windows were modified, adding $30 \mathrm{~cm}$ tall operable ventilation openings for cross-ventilation. Shading elements were added to windows and openings. For the improved $\mathrm{X} 1$ model, the construction system and strategies were quite similar to the W1 model, including the EPS-blocks concrete slab, a thermal insulation layer, thermal mass, windows configuration, shading, and blinds. The difference between both models is the air gap between the two-brick layer. For X1, the air gap is $5 \mathrm{~cm}$ wide. The reason for the similarities between $\mathrm{W} 1$ and $\mathrm{X} 1$ is that they share climatic characteristics in terms of temperature and other variables. They have many isotherm areas (areas that have an annual temperature variation from 0 to $5^{\circ} \mathrm{C}$ ). The difference between them is the high relative humidity in the tropical $\mathrm{X} 1$ area.

For the improved Y1 model, the construction system of the ceiling was changed from joist and block concrete slab to a reticular lightweight EPS-blocks concrete slab for thermal insulation. A continuous thermal insulation layer was also proposed using EPS expanded polystyrene with a thermal conductivity of $0.029 \mathrm{~W} / \mathrm{m}^{2} \mathrm{~K}$ and a width of $6 \mathrm{~cm}$. Using the insulation, the thermal masses of the brick and concrete elements were enhanced. The walls were modified, adding an extra layer of brick, with a $5 \mathrm{~cm}$ air gap between them. For better ventilation flow inside the building, $30 \mathrm{~cm}$ was added to the interior height. The façade windows were modified, adding $30 \mathrm{~cm}$ tall operable ventilation openings for cross-ventilation. Because of the high radiation in this location, the building receives unnecessary heat gains from the northern façade. To solve this problem, the improved model included shading elements for northern windows. Shading elements were added in windows and openings. Finally, for the improved Z2 model, the construction system of the ceiling was similar to the Y1 model. However, due to the extremely warm climate, a second ceiling was added, with a ventilated air gap of $15 \mathrm{~cm}$. The second concrete ceiling 
receives the direct radiation, and the cross-ventilation in the air gap dissipates the overheat. The ventilation method of this model relies on bulk airflow measures, driven by wind, to promote natural ventilation. Ventilation was enhanced also by promoting the stack effect by positioning ventilation openings near the roof (which is $20 \mathrm{~cm}$ higher than the other improved models.

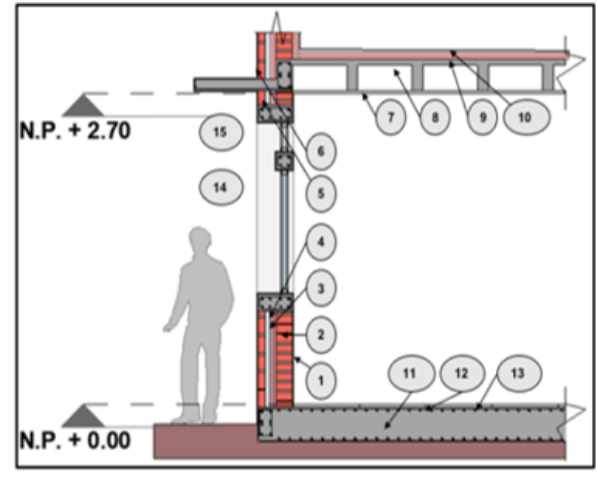

Construction System - Optimized Model - Y1 - Culiacán

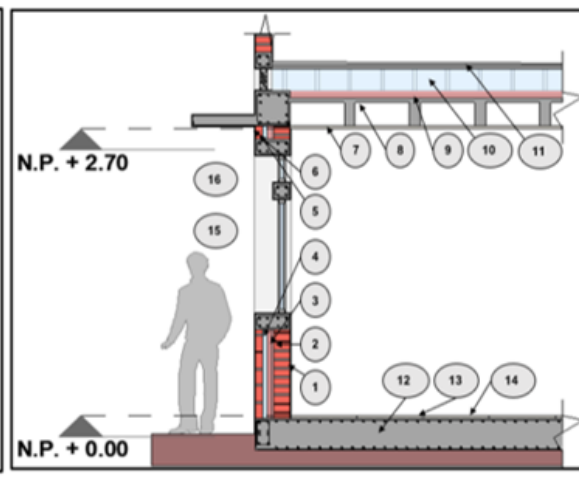

Construction System - Optimized Model - Z2 - Mexicali

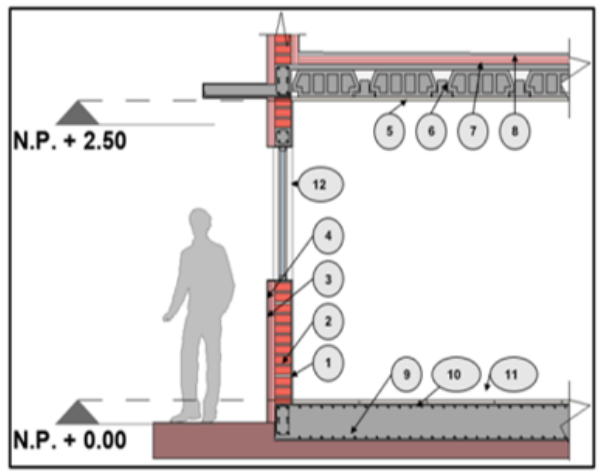

Construction System - Optimized Model - V3 - Toluca de Lerdo

Figure 10. Architectural details of the construction systems used in some of the improved models for testing. For more detailed information and the key for the numbered circles, see Appendix A.

This improved model included all the mentioned strategies, like $6 \mathrm{~cm}$ thermal EPS insulation, double brick layer with a $5 \mathrm{~cm}$ air gap, shading elements in windows, etc. The south façade windows were covered with a stationary during summer, and its leaves fall in winter (allowing direct solar heat gains). The interior height of the model was increased $60 \mathrm{~cm}$, creating a $3.30 \mathrm{~m}$ height to allow the warm air to concentrate in the upper part of the interior space.

Using the SGSAVE complementary tools, certain special characteristics were introduced to all improved models:double-glass windows with a 4-cm air gap, and windows blinds for the south façade, with an operation calendar of $30 \%$ aperture in the summer. These improved models were constructed for testing the energy performance of the mostused construction system in Mexico (reinforced concrete elements with red brick walls and a foundation bed) in the different climatic zones in the country. To obtain a wider view of the desired results, we created improved models with different construction systems. For comparing the results with the traditional system, the two most-used traditional systems after reinforced concrete and fabric were chosen: the wood construction system and the adobe-metal sheets construction system. All the bio-climatic strategies that were used for the improved models were taken from a practical guide of 101 basic rules for low energy consumption [37].

The wood construction system (Figure 11) was composed of 1.8-cm wide Triplay OSB (Oriented Strand Bond) panels and timber structure in the walls and ceiling. The floor was a foundation bed of concrete, with $60 \times 60 \mathrm{~cm}$ ceramic tile. The walls had a double Triplay OSB panel layer with a wood-cork thermal insulation 5-cm wide with a thermal conductivity of $0.04 \mathrm{~W} / \mathrm{m}^{2} \mathrm{~K}$ and a vinyl waterproof sheet for stopping condensations [38]. The adobe-metal sheet construction system (Figure 11) was composed of a reinforced concrete structure with walls with adobe blocks (mud and straw regional block). Because of the low bearing capacity of these walls, the model needs a lightweight structure for the ceiling. So, a wood-timber ceiling was proposed, with a floor composed of a foundation bed of concrete slab. The adobe-metal sheet construction is an experimental construction technique, inspired by bahareque vernacular system [39]. The bahareque system is composed of a bamboo frame structure, with a medium-height wall of adobe and a second wall of bamboo panels. The ceiling should be a lightweight structure, like straw or a light wood or bamboo latticework. For this option, the bamboo structure was replaced by a reinforced 
concrete structure (for seismic resistance), and the walls were covered by a metallic sheet (corrugated galvanized steel), which has high heat reflectance.

The technical information of the traditional materials used in the proposed model construction elements was obtained from Appendix D of NOM-020-ENER-2011 [3]. For the remaining materials, the data were obtained from the digital catalogue of the Mexican construction store Home Depot [40].

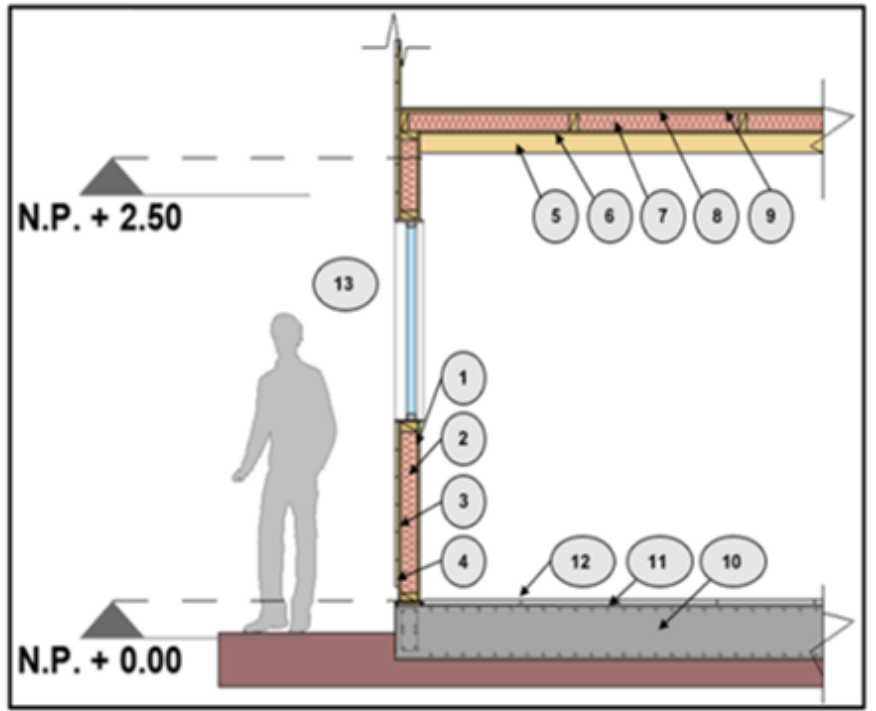

Construction System - Optimized Model - WOOD SYSTEM

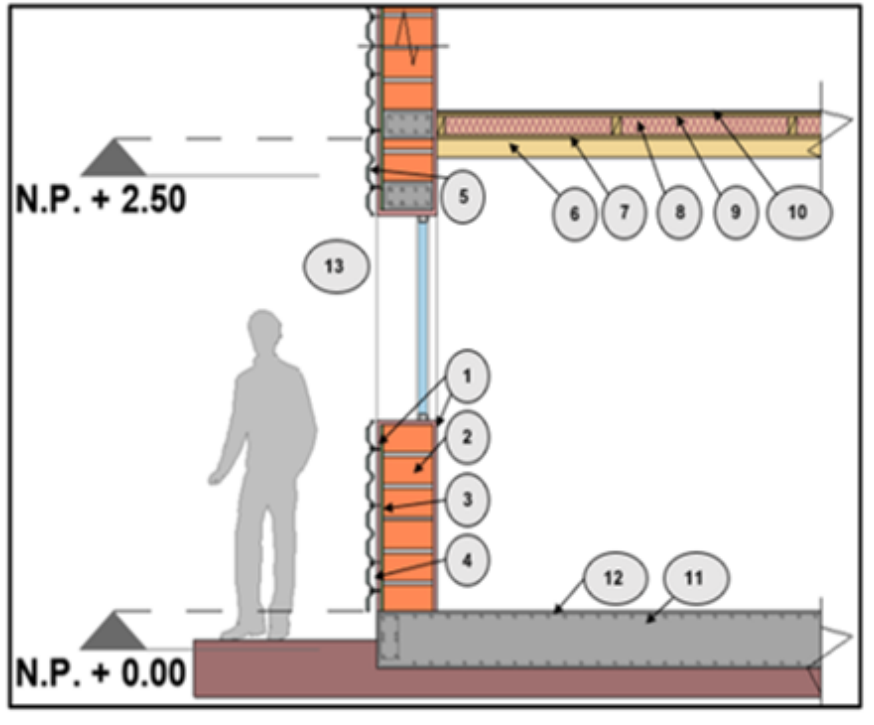

Construction System - Optimized Model - ADOBE | METAL SHEET

Figure 11. Architectural details of the two construction systems used to compare the results with the traditional reinforced concrete and fabric walls system. For more detailed information and the key for the numbered circles, see Appendix A.

\section{Results}

The final results of the testing produced several conclusions. All models were simulated in the software for verifying the standards. The following improved models met the Mexican standard: V3 and V1 with an energy savings of 20\%; V1, X1, and Y1, with an energy savings of $19 \%$; and the Z2 model, with an energy savings of $20 \%$. Compared with the $-151 \%$ of the base model, the $19-20 \%$ improvement with the the updated model is significant. Howeer, these results only show the heat gains and loses for the thermal envelope as requested by the Mexican energy standard. Open Studio SGSAVE software, using Energy Plus, simulated and calculated a wide variety of results. For example, it provides a broken-down report of the different heat gains and losses of the building. The report includes heat gains for two different season groups (winter and summer) and a classification according to transference channel.

As reported Figure 12, there are different heat gains and losses that should be analyzed. In summer, the largest heat gains of the thermal envelope occur in the external walls, windows through radiating heat gains, air infiltration, ventilation, and internal gains. For winter, the situation for heat losses also occurs for the same channels. These gains and losses can result in larger cooling demands. These results are important because they indicate the critical aspects to consider when optimizing the thermal envelope design. The Mexican standard only reports heat gains through the thermal envelope. However, the verification methods used by other entities, like the European Union, or private certifications, like LEED (Leadership in Energy and Environmental Design), consider energy demands for heating and cooling. Fortunately, Energy Plus also reports the heating and cooling demands for the evaluated project for a simulation period of one year. These are the results obtained, grouped by basic model demands, improved model demands, and energy savings percentages. 

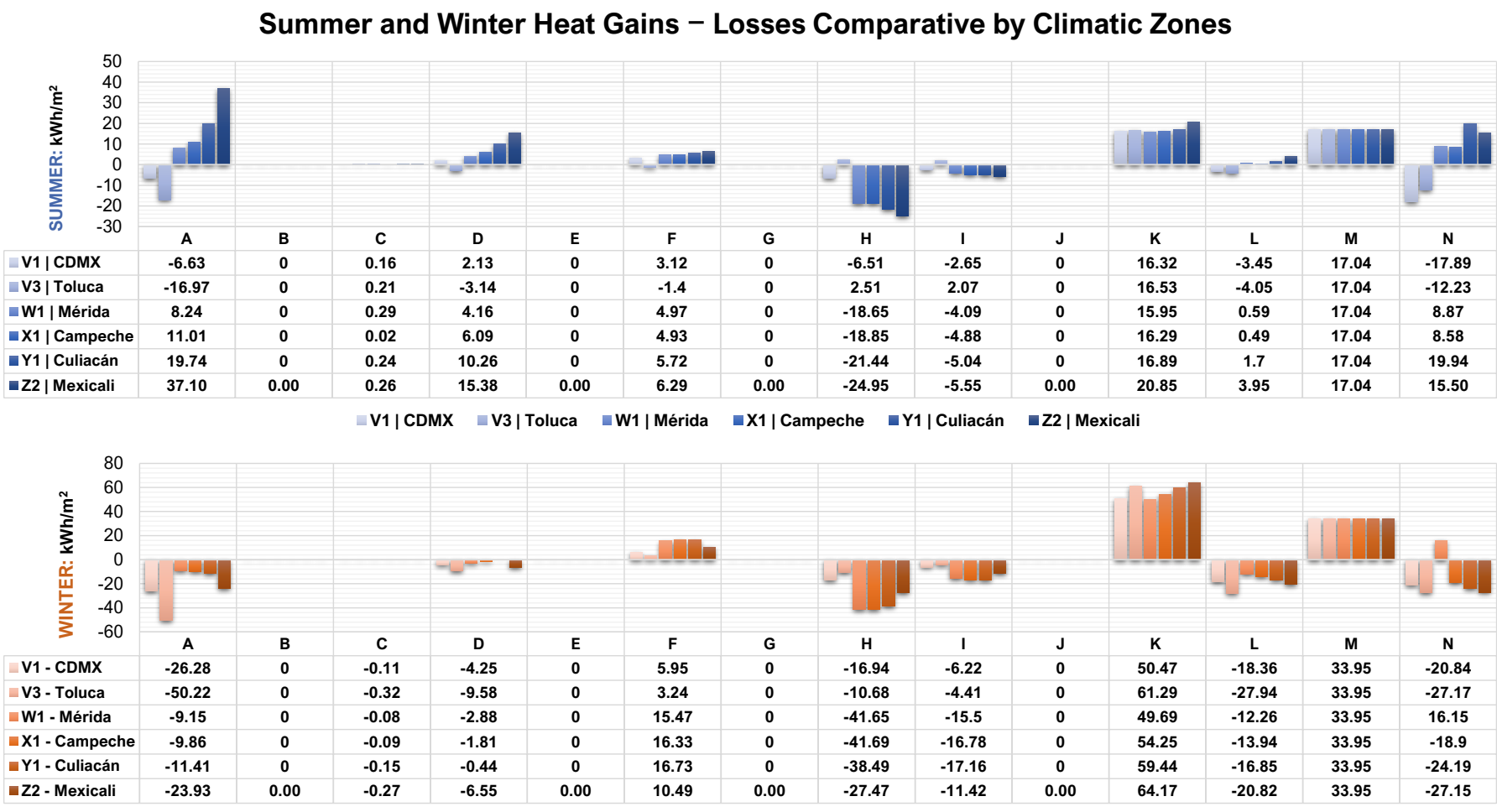

V1 - CDMX $\square$ V3 - Toluca $\square$ W1 - Mérida $₫$ X1 - Campeche $\square$ Y1-Culiacán $\square Z 2$ - Mexicali

Figure 12. Heat gains and losses of the thermal envelope for summer and winter. The heat gains are reported by heat transference channel: (A) exterior walls, (B) ground contact walls, (C) interior partitions, (D) exterior ceilings, (E) ground ceilings, (F) interior ceilings, $(\mathrm{G})$ open-air floors, $(\mathrm{H})$ ground-contact floors, (I) interior floors, (J) thermal bridges, (K) windows radiation (solar) heat gains, $(\mathrm{L})$ windows' conductive heat gains, $(\mathrm{M})$ internal gains, and $(\mathrm{N})$ air infiltration and ventilation.

\subsection{Testing Results 1: Improved Models for Climatic Zones}

For the V1 (Table 1) cooling demand, the base model needed $0.40 \mathrm{kWh} / \mathrm{m}^{2}$, the improved model needed $0 \mathrm{kWh} / \mathrm{m}^{2}$, and the savings was $100 \%$. For V1 heating demand, the base model needed $14.87 \mathrm{kWh} / \mathrm{m}^{2}$, the improved model needed $17.10 \mathrm{kWh} / \mathrm{m}^{2}$, and the savings was $-16 \%$. In this case, the V1 model meets the Mexican standards, but the improved model resulted in larger heating demands due to thermal insulation. For V3 (Table 1) cooling demand, the base model needed $0 \mathrm{kWh} / \mathrm{m}^{2}$, the improved model needed $0 \mathrm{kWh} / \mathrm{m}^{2}$, and the savings was $0 \%$, because there was no cooling demand due to the effectiveness of the thermal envelope. For V3 heating demand, the base model needed $76.26 \mathrm{kWh} / \mathrm{m}^{2}$, the improved model needed $58.69 \mathrm{kWh} / \mathrm{m}^{2}$, and the savings was $23 \%$. As shown, the energy savings are similar in both the Mexican standard and in the heating/cooling demands.

For W1 (Table 1) cooling demand, the base model needed $33.30 \mathrm{kWh} / \mathrm{m}^{2}$, the improved model needed $2.80 \mathrm{kWh} / \mathrm{m}^{2}$, and the savings was $91 \%$. For W1 heating demand, the base model needed $0.46 \mathrm{kWh} / \mathrm{m}^{2}$, the improved model needed $0 \mathrm{kWh} / \mathrm{m}^{2}$, and the savings was $100 \%$. Although the Mexican standards report energy savings of only $19 \%$, the heating/cooling demand reports savings from $91 \%$ to $100 \%$. 
Table 1. Energy simulation results of basic and improved models for cooling and heating demands, with their correspondent savings percentage.

\begin{tabular}{|c|c|c|c|}
\hline \multicolumn{4}{|c|}{ Testing Results for Cooling Demands-Improved Models } \\
\hline Climatic Zone & $\begin{array}{c}\text { Basic Cooling } \\
\text { Demand }\left(\mathrm{kWh} / \mathrm{m}^{2}\right)\end{array}$ & $\begin{array}{l}\text { Improved Cooling } \\
\text { Demand }\left(\mathrm{kWh} / \mathrm{m}^{2}\right)\end{array}$ & $\begin{array}{l}\text { Energy Saving } \\
\text { Percentage (\%) }\end{array}$ \\
\hline V1 & 0.40 & 0.00 & 100 \\
\hline V3 & 0.00 & 0.00 & 0 \\
\hline W1 & 33.30 & 2.80 & 91 \\
\hline $\mathrm{X} 1$ & 40.34 & 2.78 & 93 \\
\hline Y1 & 70.83 & 12.06 & 83 \\
\hline $\mathrm{Z} 2$ & 104.77 & 24.16 & 77 \\
\hline \multicolumn{4}{|c|}{ Testing Results Comparison for Heating Demands-Improved Models } \\
\hline Climatic Zone & $\begin{array}{c}\text { Basic Heating } \\
\text { Demand }\left(\mathbf{k W h} / \mathbf{m}^{2}\right)\end{array}$ & $\begin{array}{l}\text { Improved Heating } \\
\text { Demand }\left(\mathrm{kWh} / \mathrm{m}^{2}\right)\end{array}$ & $\begin{array}{l}\text { Energy Saving } \\
\text { Percentage (\%) }\end{array}$ \\
\hline V1 & 14.87 & 17.10 & -16 \\
\hline V3 & 76.26 & 58.69 & 23 \\
\hline W1 & 0.46 & 0.00 & 100 \\
\hline X1 & 0.00 & 0.00 & 0 \\
\hline Y1 & 0.59 & 0.20 & 66 \\
\hline Z2 & 26.73 & 20.68 & 23 \\
\hline
\end{tabular}

For X1 (Table 1) cooling demand, the base model needed $40.34 \mathrm{kWh} / \mathrm{m}^{2}$, the improved model needed $2.78 \mathrm{kWh} / \mathrm{m}^{2}$, and the savings was $93 \%$. For X1 heating demand, the base model needed $0 \mathrm{kWh} / \mathrm{m}^{2}$, the improved model needed $0 \mathrm{kWh} / \mathrm{m}^{2}$, and the energy savings was $0 \%$ because this climatic zone is tropical and does not require energy for heating.

For Y1 (Table 1) cooling demand, the base model needed $70.83 \mathrm{kWh} / \mathrm{m}^{2}$, the improved model needed $12.06 \mathrm{kWh} / \mathrm{m}^{2}$, and the savings was $83 \%$. For the $\mathrm{Y} 1$ heating demand, the base model needed $0.59 \mathrm{kWh} / \mathrm{m}^{2}$, the improved model needed $0.20 \mathrm{kWh} / \mathrm{m}^{2}$, and the savings was $66 \%$. Analyzing this semi-arid zone with high temperature range (27 to $35{ }^{\circ} \mathrm{C}$ for $50 \%$ of the year), we found that the cooling demand became more relevant and expensive than heating demand. So, $66 \%$ energy savings translates into lower electricity cost for the model.

For the Z2 (Table 1 cooling demand, the base model needed $104.77 \mathrm{kWh} / \mathrm{m}^{2}$, the improved model needed $24.16 \mathrm{kWh} / \mathrm{m}^{2}$, and the savings was $77 \%$. For the $\mathrm{Z} 2$ heating demand, the base model needed $26.73 \mathrm{kWh} / \mathrm{m}^{2}$, the improved model needed $20.68 \mathrm{kWh} / \mathrm{m}^{2}$, and the savings was $23 \%$. This climatic zone with the most extreme conditions had high energy demands for cooling. The heating is needed at night due to being located in a desert area. Although the energy savings are the lowest compared with the other climatic zones, they represent significantly lower energy consumption.

The energy label, graphic proposal and energy demand results, for each climatic zone, are displayed on Figure 13. 

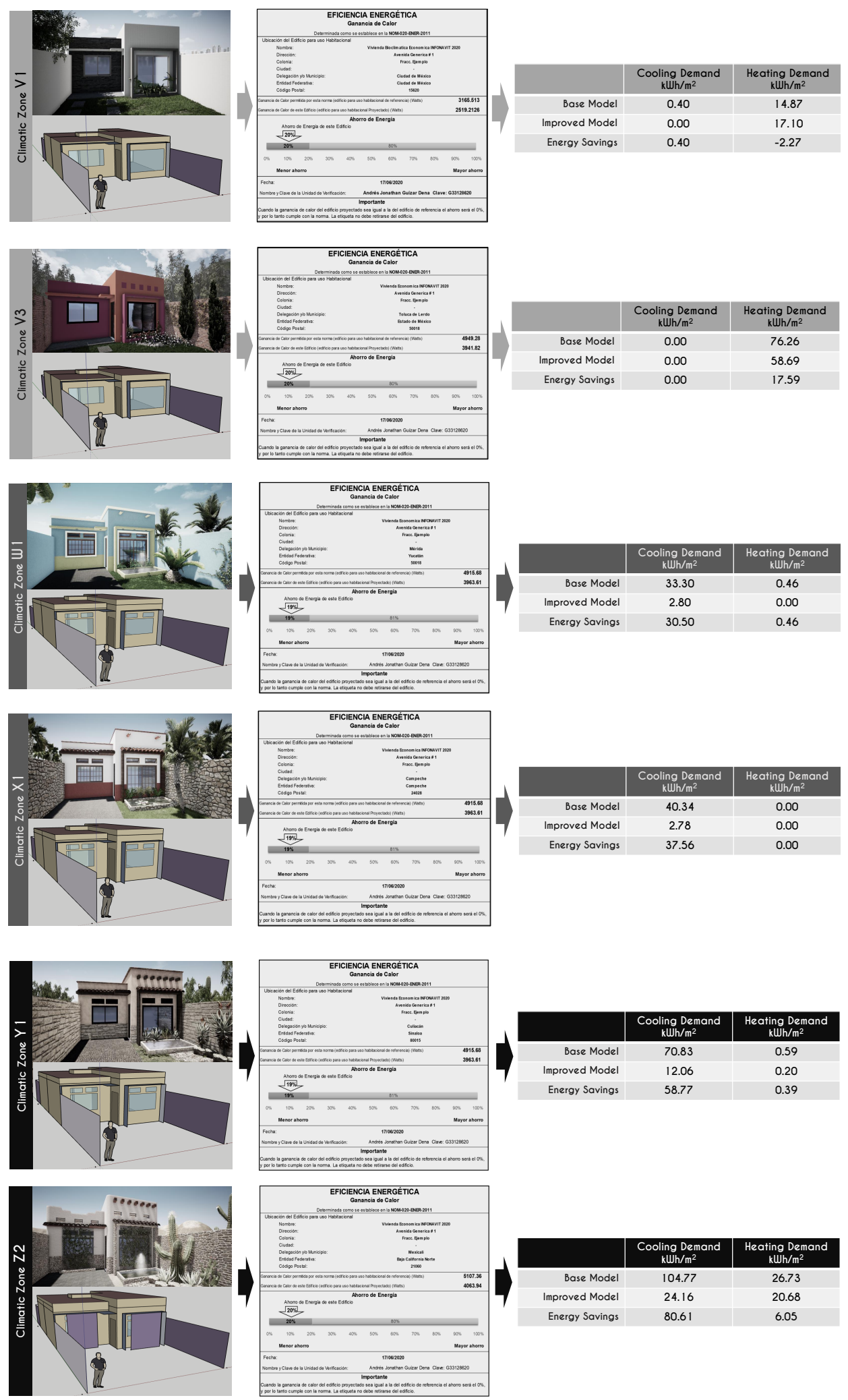

Figure 13. Testing results for the proposed geometric model, Mexican standard certification label, and comparison of heating and cooling demand simulations between the base model and the improved model for Mexican standard certification. 


\subsection{Testing Results 2: Comparison between Different Construction Systems}

The previous results only apply to the traditional reinforced concrete structure fabric walls system. New simulations were run to test the other two proposed construction systems: wood and adobe-metal sheet. Because the goal of this second testing was to quickly compare the systems, the most extreme climatic zones were chosen: V3, Toluca de Lerdo, for the coolest climate zone; Z2, Mexicali, for the warmest climate zone; and V1, Mexico City, for the temperate climate zone. Before running the simulations, there was a problem of units that needed to be addressed. The Mexican energy standard NOM020-ENER-2011 reports the heat gains of the thermal envelope in Watts. The Energy Plus engine reports the heat gains of the thermal envelope in kilowatts hour per square meter $\left(\mathrm{kWh} / \mathrm{m}^{2}\right)$. For precise comparison, the results of both methods, the complementary simulation report was modified to obtain a wider range of results. For this comparison, two indicators were taken: window total heat loss rate (for radiation heat gains) and surface inside face conduction heat transfer rate (for conductive heat gains). Both indicators are expressed in Watts. The results obtained from the simulations are depicted in Figure 14.

Energy Plus considers other heat sources and heat gains for the projected building. The internal gains, for example, are an important source of heat for building interiors. In accordance with the conclusions of Turley et al., occupancy heating plays an important role in internal heating and energy performance: "Occupancy-aware heating, ventilation, and air conditioning (HVAC) control offers the opportunity to reduce energy use without sacrificing thermal comfort. Residential HVAC systems often use manually-adjusted or constant set-point temperatures, which heat and cool the house regardless of whether it is needed. By incorporating occupancy-awareness into HVAC control, heating and cooling can be used for only those time periods it is needed" [41]. Turley et al. found that occupancy-aware control of HVAC equipment produces important energy savings due to the contribution of internal gains and no-waste-energy intervals.

This sensitive control theory of HVAC equipment for the proposed new building is supported by Jonghoon's findings about achieving an equilibrium between thermal comfort and the energy use of a building: "Despite the improvement of mechanical thermal models associated with advanced statistical tools have been performed, there is a necessity of the investigation of sensitive control models for supply heating and cooling energy into a single space scale which can be closely related to users' workability and productivity" [42]. Constructing a simulation of HVAC equipment with sensitive control of set-point temperature could be achieved using Energy Plus with a detailed model and advance parameters definition.

The behaviors of the three systems were similar for the three representative climatic zones. The construction system with the lowest heat gains was the traditional system of reinforced concrete and fabric walls. The construction system with the worst performance and the highest heat gains in the three climatic zones was the wood system.This phenomenon occurs because of wood high insulation properties. Wood restricts heat transfer from inside to outside, promoting heat accumulation for interior spaces. For cold climatic zones, this phenomenon helps for lowering heating demand. But for warm climatic zones, the effects are different. In summer, wood does not dissipate heat properly, and the interior spaces have unwanted heat accumulation. The same effect occurs for arid warm and desertic climatic zones. The heat accumulation increases building cooling demands. And for Mexican normative, by absorbing and not dissipating heat gains, wood reported high heat gains balance. In contrast with concrete and adobe systems, because of the breath-ability characteristics of their principal materials.

Notably, the aim of this second testing exercise was to perform a quick comparison between the different systems. For detailed results and exact behaviors, we strongly recommend additional, separate research. Some important findings to highlight from the previous graphs include: The adobe-metal sheet construction system showed remarkable performance in the three climatic zones, although it did not have the best performance. 


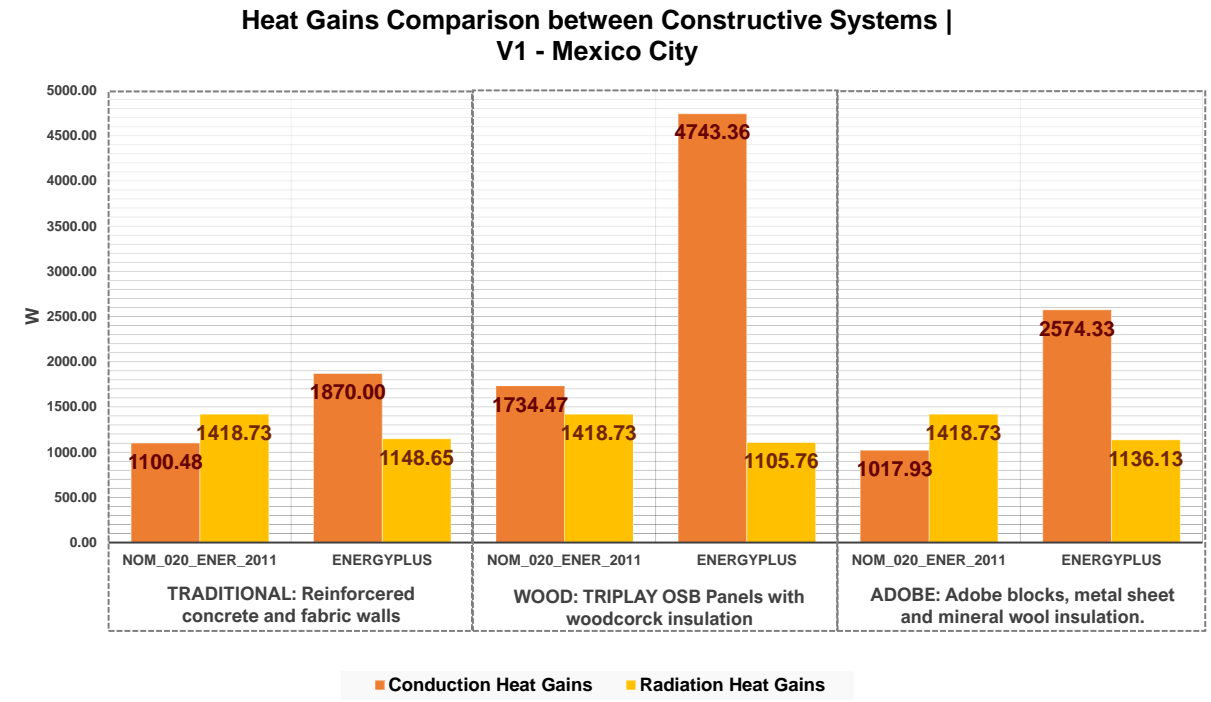

Heat Gains Comparison between Constructive Systems | V3 - Toluca de Lerdo

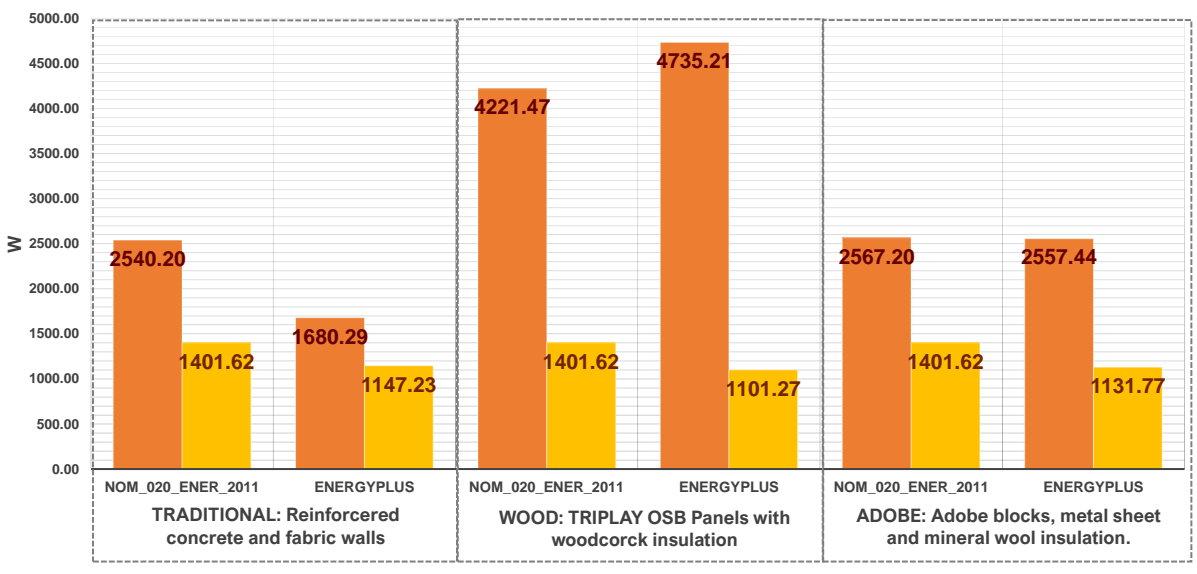

- Conduction Heat Gains $\quad$ = Radiation Heat Gains

Heat Gains Comparison between Constructive Systems |

Z2 - Mexicali

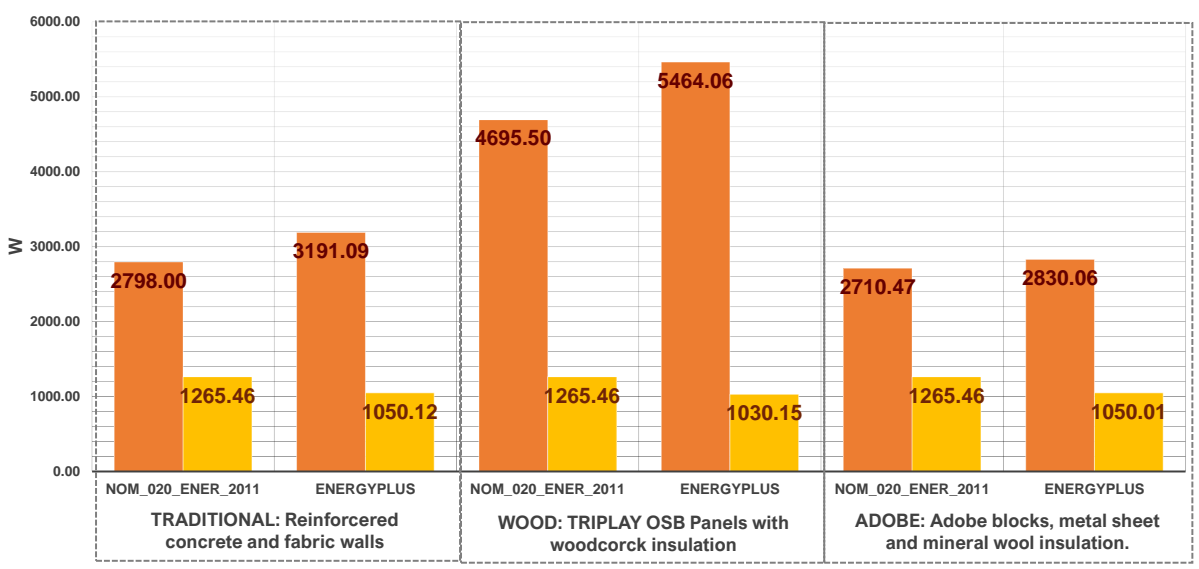

= Conduction Heat Gains $\quad$ Radiation Heat Gains

Figure 14. Comparison of the heat gains of the thermal envelope for the three construction systems chosen for testing: traditional reinforced concrete and fabric walls, wood, and adobe with metal sheet. The two graphs with the NOM-020-ENER-2011 label show the calculated heat gains results using the standard method. The two graphs with the Energy Plus label show the heat gains results using the simulation tool software. 
It provides a good staring point for new inquiries because this construction system is most environmentally friendly. It produces less waste and has lower primary energy needs for its construction than the traditional reinforced concrete system. The results showed that the three construction systems perform their best in V1, Mexico City, having low heat gains.

This results proved the viability of using vernacular construction techniques for improving the energy efficiency of housing projects. A similar study was developed by Zhai and Previtali. They selected a variety of vernacular techniques (in accordance with climatic zones) and followed a similar methodology to ours. They creates a construction techniques and materials catalogue, and split them into categories by roof, wall, and floor. After comparing and cataloguing the materials and systems, several simulation were run with BEopt software (developed by the U.S. Department of Energy). The computer optimization tool was able to find a combination of vernacular construction techniques that exceeded both the IECC (International Energy Conservation Code) reference case and the observed vernacular case, revealing the potential room for improvement in building codes and vernacular architecture [43].

The simulation also helped to prove the efficiency of the proposed bio-climatic strategies. This helps the architects and energy managers of a project by proving the viability of these design strategies with data. The ventilated air gaps in the warmest climatic zones help to increase the energy savings.This finding agrees with Oropeza-Perez et al. who stated, "Through a sensitivity analysis, it is found that the efficiency of natural ventilation under warm conditions is affected by the following inputs in this order: climate conditions, windows opening schedule, materials of construction, built area, and number of occupants. The potential for saving energy by using natural ventilation is more when the dwelling materials of construction have high heat capacity and the dwelling is located in a hot-dry climate. In a hot-humid climate, low heat capacity materials and natural ventilation help to lower the indoor temperature" [44].

We highlight the differences between the NOM-020-ENER-2011 and Energy Plus results. The Mexican standard results are similar, with very little difference between climatic zones. Conversely, the Energy Plus results have a larger difference between them. This shows how the Mexican standard only considered reference values and standardized coefficients for climate and thermal envelope characteristics, whereas Energy Plus considers more specific variables, like internal gains, shadow elements, and location. In other words, Energy Plus results provide precise information about a project, with its particular characteristics; however, the building must have limited complexity, and the results are basic. As concluded by the authors of the Science Direct article Optimization Tools for Building Energy Model Calibration: "On the one hand, parametric analysis results are exhaustive and show the entire spectrum of results for a given problem, providing a complete picture of the possibilities to consider. On the other, this straightforward 'brute force' approach proved to be quite resource-demanding both regarding calculation time and computational capacity, preventing its implementation when a complex building simulation model is analyzed" [45].

\section{Discussion}

\subsection{Benefits of Using Energy Plus vs. Standard Method}

The results produced by the Mexican standard report and Energy Plus report show a variety of differences. The Mexican standard report considers the limited scope of heat gains and verification of standard compliance. Instead, Energy Plus offers a wide variety of possible results (depending on the simulation parameters selected) from energy demands to primary energy consumption (depending also on the level of detail in the model and definition of the project).

Energy Plus results and capabilities are already being used for building energy performance in several softwares and tools. For example, Giancola et al. recorded a map of energy saving potential with a geographic information system (GIS) by applying refurbishment measures and using simulation results [46]. Another direct application for the proposed 
verification method includes building project management using Building Information Models (BIM). BIM management is a field recently popularized in the construction industry that involves applying a precise team work flow in different departments (structure, cost, engineering, installations, and architectural project) for correctly managing a project. By merging this BIM software with energy simulation software, the manager can analyze and integrate the results, so the pertinent design and engineering decisions can be made on time [47]. Auto-desk developed an energy simulation complement, Revit, for BIM software [48]. With the starting point provided by this research, an energy simulation complement for Mexico could be developed for a BIM management program.

Connecting the Energy Plus simulation tool with the Mexican standard could facilitate applicability to popular architectural and engineer tools on the market. In Spain, the authorities took advantage of simulation tools' practicality to make the energy certification process fast and easy for the construction industry. Therefore, Mexican authorities should follow the same path by starting to include the use of simulation tools for applying the energy standards.

Using the energy simulation engine, the user can obtain a wide range of results, but the results depends on the scope of analysis. Several options of simulation software are available on the market depending on the design process stage in which the user is involved (conception, project, or execution), and the complexity of the work (basic, intermediate, or advanced). Each simulation tool evolves from detailing and requirements, depending on if the user needs a basic program of intuitive interface tools or a specialized study with a wide scope (analyzing different project phases and application magnitudes) [49]. With Energy Plus, the user can enter other important building variables excluded by the standard, like occupation calendar, location characteristics, and HVAC equipment design. The new results allow the user to analyze other variables in addition to those considered in the Mexican standard results of thermal envelope heat gains, such as energy demands, primary energy used for building procedures, an estimated consumption of electricity and sanitary hot water, total hours where the set-point for comfort is not met, and the precise elements that have heat gains or losses (windows, walls, internal gains, soil, ceiling, etc.). Our results pave the way for a parametric analysis tool in the quest for a complete energy verification model. "The parametric analysis tool demonstrates the potential of parametric analysis, in finding optimal building envelope solutions in terms of operational energy, embodied CO2eq emissions and embodied energy. In the future, the parametric analysis tool may be used for setting energy performance goals and benchmarks, optimizing renewable energy and passive systems, integrating architectural features, minimizing changes during construction and integrating building systems" [50].

\subsection{Aims Fulfillment: Why Improved Instead of Optimized?}

The aims of the testing methodology were fulfilled by designing an energy model for verification of building compliance with the standard. Notably, the principal aim of the proposed model is to verify regulation compliance in this study. The testing method uses improved models and not an optimized model. The reasons for this are as follows.

Mexican social housing differs from the European or American context. The Mexican government does not provide houses directly for the population. Instead, the government provides loans and financial aid for workers. The principal source of housing acquisition for workers and the poor is self-construction. Due to the economic informality and high poverty rates, those requiring social housing experience problems acquiring a loan, mortgage, or financial aids, so the workers save money and build their own houses [11]. Considering the social housing situation, the proposed model prioritizes energy certification with affordable construction plans. An optimized model that complies with the net-zero carbon buildings 2030 target is a distant and inapplicable aim for Mexican social housing. There is no local suppliers for the required equipment, like thermal-break profiles or high-tech materials, so they need to be imported at high prices. Another problem is the lack of public support for self-construction improvements. To increase economic savings during the construction 
process, self-constructors prefer to use traditional techniques, and avoid investing in specialized studies, like structural or energy performance analyses. This situation provoked an increase in informal social housing and urban planning problems.

So, to adapt the proposed model for application to the self-construction reality, we compared the energy performance results between the three most-used traditional construction systems. The simulation showed promising results, like the good efficiency of the adobe system for thermal envelope heat gains. The adobe system is well-built by the national labor force and works for the majority of the climatic zones. Adobe is a good material choice for implementing thermal mass strategy, and is more affordable than the reinforced concrete system.

The reason for preferring improved models over an optimized model is for testing the proposed model on a more accurate social housing situation. It is preferable to test and verify compliance with the regulation using affordable and simple bio-climatic strategies (for achieving the energy standard compliance and obtaining an energy efficiency label), rather than implementing complex strategies, high-tech materials, and specialized procedures for achieving optimized results. This does not mean that an NZEB housing model is impossible: the implementation should be step by step. First, the improved models should be promoted for increasing the awareness of the Mexican population about the benefits of energy efficiency strategies. If the market and the authorities increase the application of the Mexican energy standard, the demand for better techniques and materials will increase too. Mexico's authorities are beginning to implement sustainable practices for construction, though there is still a long way to go to achieving the same level of energy efficiency awareness and legislation as in the European Union.

How does the research is aligned with the vision set by Mexico Green Building Council? The Mexico Green Building Council recognizes the NOM_020_ENER_2011 as a mandatory normative, although its applicability has not been strictly monitored by authorities. The research helps the realization of their vision, by focusing on make energy saving building strategies available for a larger segment of population. The Green Council works for bringing educational tools for sustainable building practices, and the proposed model will help as a tool for testing and certifying the norm compliance with social housing models [51].

The proposed model implements technical data from the traditional construction systems available in Mexico. With the climatic zoning designed with Mexican meteorologic information, the model served for testing the building systems energetic performance, their compliance with the national normative, and the possible energy savings by applying several strategies. The model covers several energy requirements for EDGE and LEED certifications. Not all requirements, but is a good starting point for implementing Green Building Council principles of energy performance for self-construction and Mexican social housing. the Mexico Green Building Council encourages the NOM_020_ENER_2011 learning and knowledge for building professionals because of its mandatory use not only in building energy performance, but also because of its utility for materials and equipment certification (home appliances, insulation materials, electric materials, etc.) [52].

How does the proposed model help the AEC (Architecture, Engineering and Construction) Industry for achieving savings for energy consumption? The model design strategies for improvement are oriented for energy savings in operation phase. It did not consider other life cycle stages, like materials extraction or building. But it is possible to make a comparative for energy consumption reduction with an Energy plus report. The normative applied on temperate climatic zones is not functional.

As shown in Figure 15, the normative applied on temperate climatic zones is not functional. The improved model that complied with the energy normative, had higher energy consumption rate than the basic model, resulting on a $1 \%$ increment on energy consumption, and a 10\% increment of primary energy. But considering that only 10 of 31 Mexican states are classified as tempered climates, the proposed model is applicable and functional for $60 \%$ of national territory. 
For cold climatic zones (Figure 15), the proposed model showed more efficiency than temperate climates. The improved model that complied with the energy normative, reported lower energy consumption rate, resulting on energy savings of 19\% compared to basic model results. For primary energy, the improved model reported energy savings of $21 \%$ compared to basic model results. A $20 \%$ of energy savings tendency for heating demand cases is a competitive value considering that 10 of 31 Mexican states are classified as cold climates.

\begin{tabular}{|c|c|c|}
\hline \multicolumn{3}{|c|}{ V1 - México City } \\
\hline & Energy Consumption $\left(\mathrm{kWh} / \mathrm{m}^{2}\right)$ & Primary Energy $\left(\mathrm{kWh} / \mathrm{m}^{2}\right)$ \\
\hline Base Model & 45.5 & 97.1 \\
\hline Improved Model & 46.0 & 106.7 \\
\hline \multicolumn{3}{|c|}{ Savings (\%) } \\
\hline & -1.1 & -9.9 \\
\hline
\end{tabular}

\begin{tabular}{|c|c|c|}
\hline \multicolumn{3}{|c|}{ V3 - Toluca } \\
\hline & Energy Consumption $\left(\mathrm{kWh} / \mathrm{m}^{2}\right)$ & Primary Energy $\left(\mathrm{kWh} / \mathrm{m}^{2}\right)$ \\
\hline Base Model & 107.5 & 202.7 \\
\hline Improved Model & $\mathbf{8 7 . 6}$ & 160.4 \\
\hline \multicolumn{2}{|c|}{ Savings $(\%)$} \\
\hline & 18.5 & 20.9 \\
\hline
\end{tabular}

\begin{tabular}{|c|c|c|}
\hline \multicolumn{3}{|c|}{ Z2 - Mexicali } \\
\hline Base Model & Energy Consumption $\left(\mathrm{kWh} / \mathrm{m}^{2}\right)$ & Primary Energy $\left(\mathrm{kWh} / \mathrm{m}^{2}\right)$ \\
\hline Improved Model & 159.3 & 401.9 \\
\hline \multicolumn{2}{|c|}{$\mathbf{7 3 . 7}$} & 181.9 \\
\hline & Savings (\%) \\
\hline
\end{tabular}

Figure 15. Comparative Results of Energy Consumption and Primary Energy for the three most representative climatic zones, with their correspondent energy savings percentage.

Remembering the statistics published by INEGI census of 2018, $40 \%$ of the northern states' families use air conditioning, and their principal energy consumption waste is electricity (used for HVAC equipment operation). With this context, the results listed in Figure 15 are promising. The improved model that complied with the energy normative, reported lower energy consumption rate, resulted on energy saving of $54 \%$ compared to basic model results. For primary energy, the improved model reported energy savings of $55 \%$ compared to basic model results. For Warm climatic zones, the proposed model reduces by half the building total energy consumption. A $50 \%$ energy saving rate tendency, applicable for 11 of 31 Mexican states with warm climatic classification, is enough for implementing the proposed model at least for this type of climatic zone.

In conclusion, the proposed model reported acceptable energy savings for 21 of 31 Mexican states. In other words, the model is effective and applicable for at least $60 \%$ of states, and a $60 \%$ of total national territory. It has enough potential market for promoting its application and development, with a national mean energy saving rate of $24 \%$ for energy consumption and $21 \%$ for primary energy.

\section{Conclusions}

In this study, we pursued four principal aims. The first aim was the creation of new climatic zoning for Mexico (with a local weather database) for delimiting the winter and summer severity for each capital city state. The actual climatic zoning available was developed by UNAM and considers several geographic and meteorological statistics. In this regard, we concluded that the proposed climatic zoning shares similarities with the Spanish climatic zoning, so this new zoning is compatible with the Open Studio and 
SGSAVE work schemes. This compatibility will help with the adaptation of SGSAVE software to the Mexican market.

The second aim was the study of the Mexican energy standard (NOM-020-ENER-2011) for its application in the proposed add-on for Open Studio. For the verification method, reference values and directives were analyzed and applied. Fortunately, Open Studio add-on software was found and used for verifying meeting the standard requirements. We concluded that the Mexican standard has the potential to be adapted to and included in the software. For now, the complement offers a simple report of verification of whether the project complies with the standard, and a final list of radiation and conduction heat gains for the proposed and reference building. Analyzing the results obtained from the testing exercise, we concluded that the standard should be updated on the add-on by programming the new directives and reference values. First, it is important to promote the use of the Mexican standard for motivating implementation of the reference values and directives at present. The strict application of the standard by the relevant authorities should involve promoting the benefits of energy demands/consumption simulations.

The third aim was to research and construct a catalogue of the principal and traditional construction systems in Mexico. Using a public census of Mexican housing, we determined the principal construction system used for walls, ceilings, and floors. By identifying the materials that compose each system, a material catalogue was developed and uploaded in a single file of SGSAVE for the fourth aim. We concluded that, like the standardverification directives, the information can be adapted for the software and programmed for the Mexican SGSAVE version. However, some additional technical information should be researched and included for new materials (like specific heat). The SGSAVE version includes the most-used construction materials in Spain, the entire Saint Gobain catalogue, and some specialized materials available in Europe. For the new version, some vernacular and manual techniques should be studied and included, like bahareque, adobe, and palmleaves ceiling. In other words, for completing the catalogue, more profound research to obtain vernacular material technical data is needed.

For the fourth aim, a testing exercise of the verification method was performed. A base model was designed to obtain initial results. Then, we improved/specified the base model for the most common climatic zones. We verified the standard, resulting in all improved models complying with the directives, and we compared the energy standard and Energy Plus results. For the final test, the proposed models of two other construction systems (wood and adobe/steel) were simulated and the results were compared with those for the reinforced concrete system. We found that the proposed model worked in all the tested models for achieving its goal of verifying the compliance with the standard. Although the model succeed for verifying the standard, it did not achieve the same energy savings level for all climatic zones; one zone showed a higher energy demand than that of the base model. An implementation and reshaping of the Mexican standard is recommended for ensuring a minimum level of energy savings for all climatic zones.

We also demonstrated the differences between the Mexican standard and Energy Plus reports. Energy Plus provides a more complete document with specified heat gains sources, virtual energy demands by an HVAC ideal loads scheme (for design references on the definitive HVAC equipment design), etc. We fulfilled our four aims and proved the viability of developing a Mexican SGSAVE version with a local verification method of compliance with the energy standard, with some pending research aims to be fulfilled in future works.

By constructing an adequate tool, the energy standard could be improved into a complete environmental regulation. The environmental standard official report would provide not only verification of meeting the standard; it will also serve to indicate the economic value of a property, the reliability of a mortgage credit, and the fulfillment of energy credits toward a private environmental certification. In conclusion, by knowing all the benefits of improving the existing standard with software within a simulation engine, 
we can verify and prove the differences between the results before and after the changes between methods.

\title{
Further Research
}

After summarizing all the results of the research, some initial aims were completed. However, other issues remain outstanding. All research projects lead to other starting points for new research. These are the pending aims:

1. The final development of an SGSAVE version for the Mexican standard and context: At the moment, the complementary script only offers the final verification results, analyzing the heat gains. The SGSAVE Mexican version should include an energy performance verification, including building performance with HVAC ideal loads, detecting the elements that more strongly influence the heat gains report, etc.

2. Self-construction energy performance guide: A direct method for conducting the verification in practical use for social benefits is the creation of a self-construction manual with public coverage. This manual should promote the use of vernacular construction systems, and provide the energy performance results for their promotion.

3. Economic viability of certified projects: It is important to prove to the market that a certified building meeting the Mexican energy standard is an attractive business, by evaluating possible usable technologies. One of the principal technologies promoted by this guide will be the photovoltaic panel due to the potential the country has for solar energy harvesting. All climatic zones have a high solar energy collection potential (from 1600 to $1900 \mathrm{kWh}$ per year).

These research opportunities should be explored, taking advantage of professional tools like Energy Plus, Open Studio, and SGSAVE. These are the initial steps of constructing a complete energy certification for Mexico, but there is more work to be done. In Critical Features of Energy Simulation for Single Housing, the authors explained: "These results are useful and beneficial for making certifications, comparing with previous references, checking other alternatives, developing individual and global improvements. Some results allow the integration of costs, make comparisons from a base case or consecutive simulations" [49].

Author Contributions: Conceptualization, All authors; Methodology, A.J.G.D.; Validation and Formal Analysis, all authors; Investigation, Resources, and Data Curation, A.J.G.D.; Writing-Original Draft Preparation, A.J.G.D.; Writing — Review \& Editing, Visualization, Supervision, all authors. All authors have read and agreed to the published version of the manuscript.

Funding: This research received no external funding.

Institutional Review Board Statement: Not applicable.

Informed Consent Statement: Not applicable.

Data Availability Statement: Not applicable.

Conflicts of Interest: The authors declare no conflict of interest.

\author{
Abbreviations \\ The following abbreviations are used in this manuscript: \\ ASHRAE American Society of Heating, Refrigerating and Air-Conditioning Engineers \\ BCL Building Component Library \\ BEM Building Energy Model \\ BIM Building Information Model \\ BMS Building Management Systems \\ CONAFOR Comision Nacional de Recursos Forestales \\ CONUEE Comision Nacional del Uso Eficiente de la Energia
}




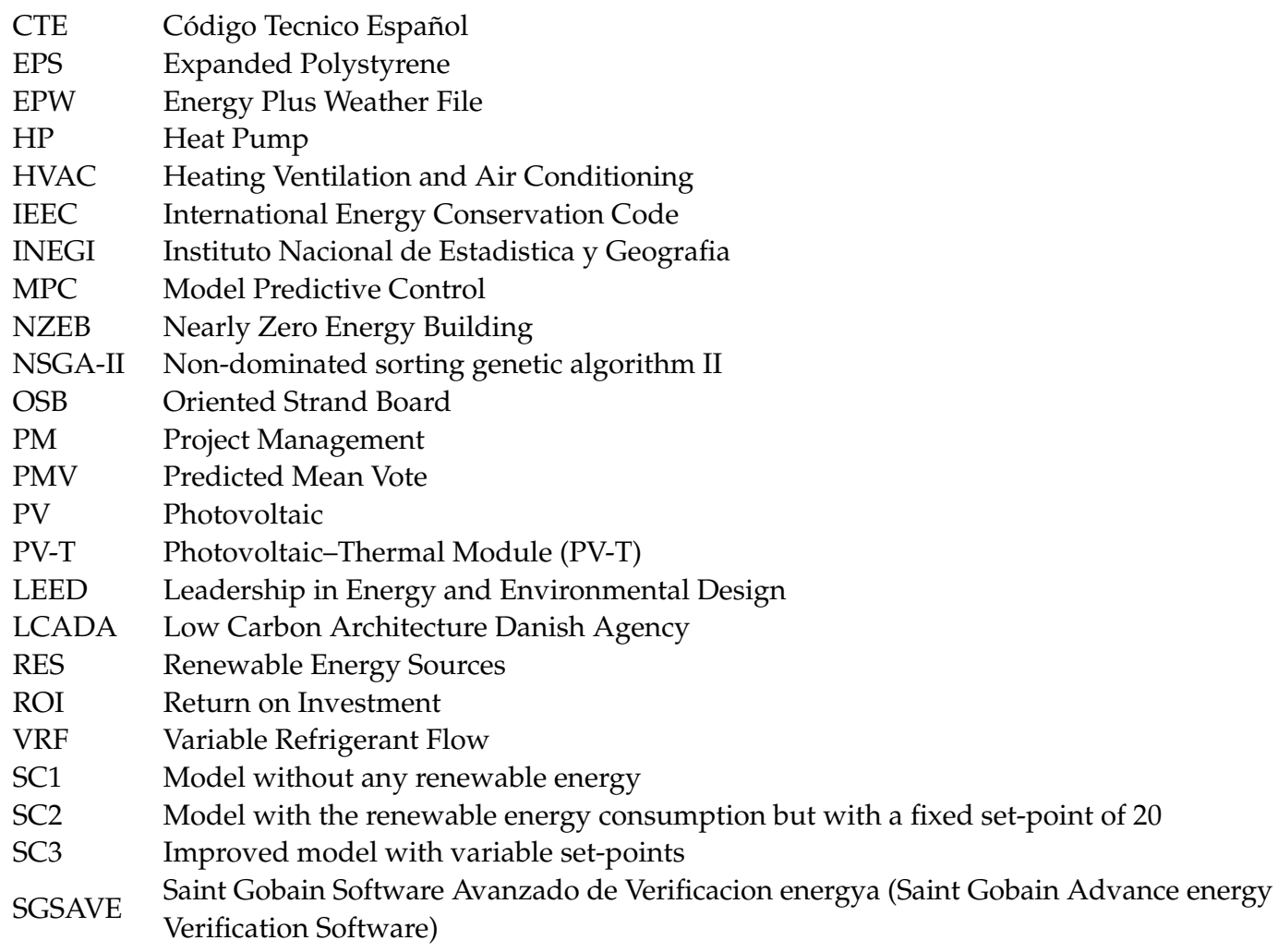

\section{Appendix A. Summary of Results}

The construction system proposed for the basic and improved models used in the test exercise is described in detail on the following diagrams:

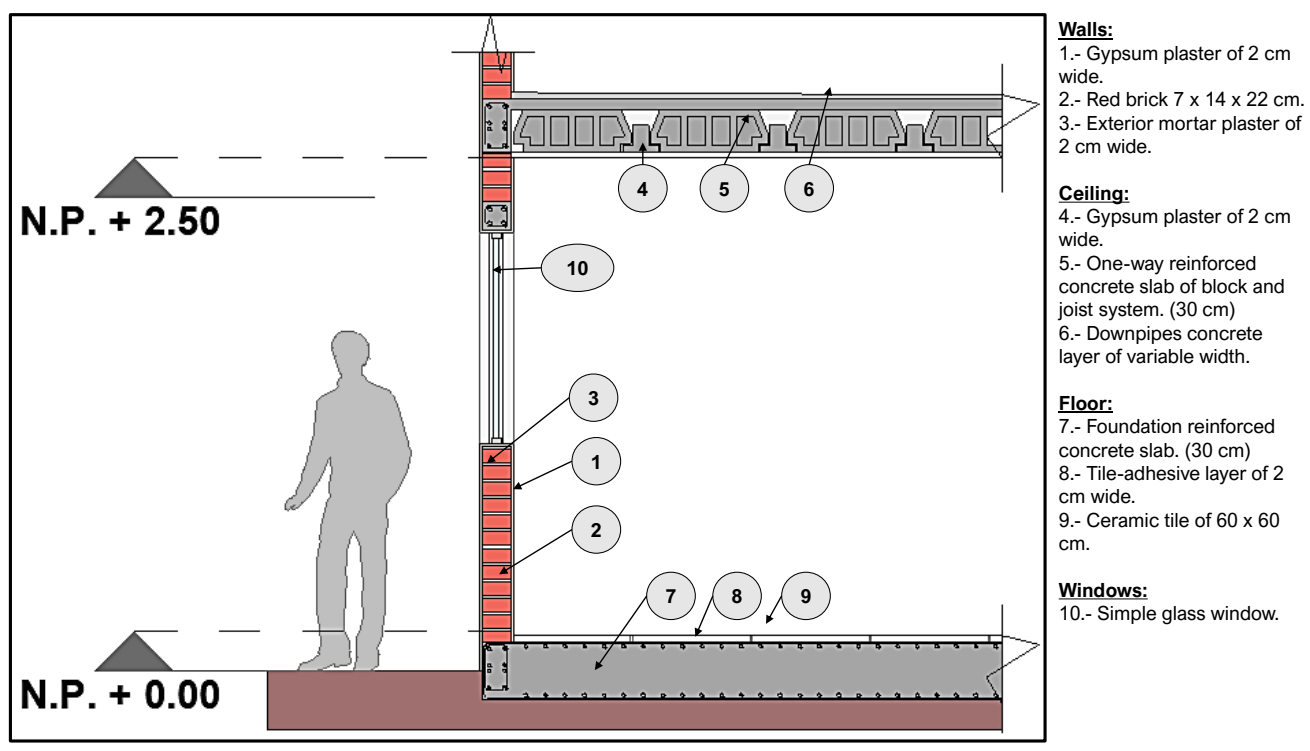

Figure A1. Construction details of the proposed base model. 


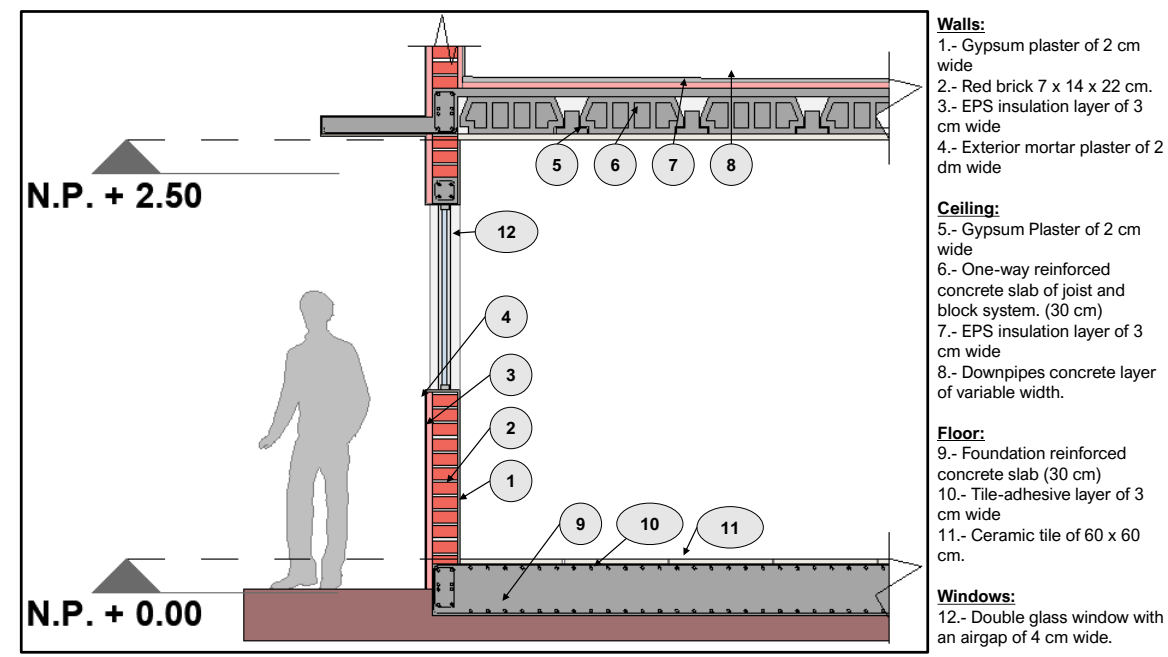

Figure A2. Construction details of the improved model of the V1 climatic zone, Mexico City.
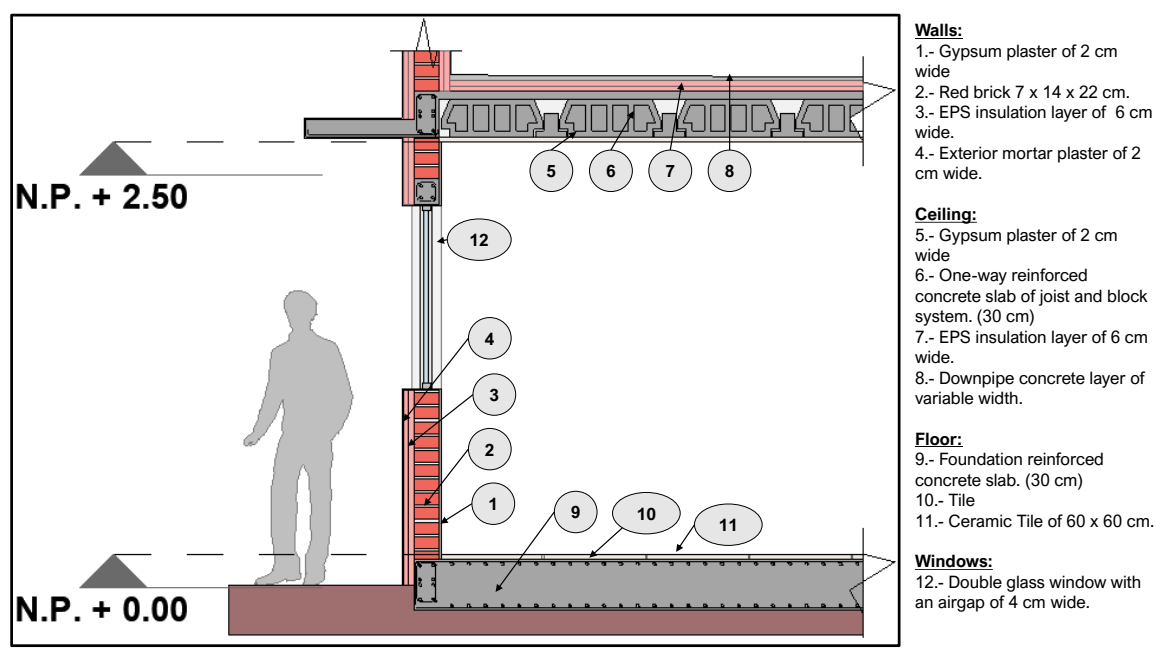

Figure A3. Construction details of the improved model of the V3 climatic zone, Toluca de Lerdo.
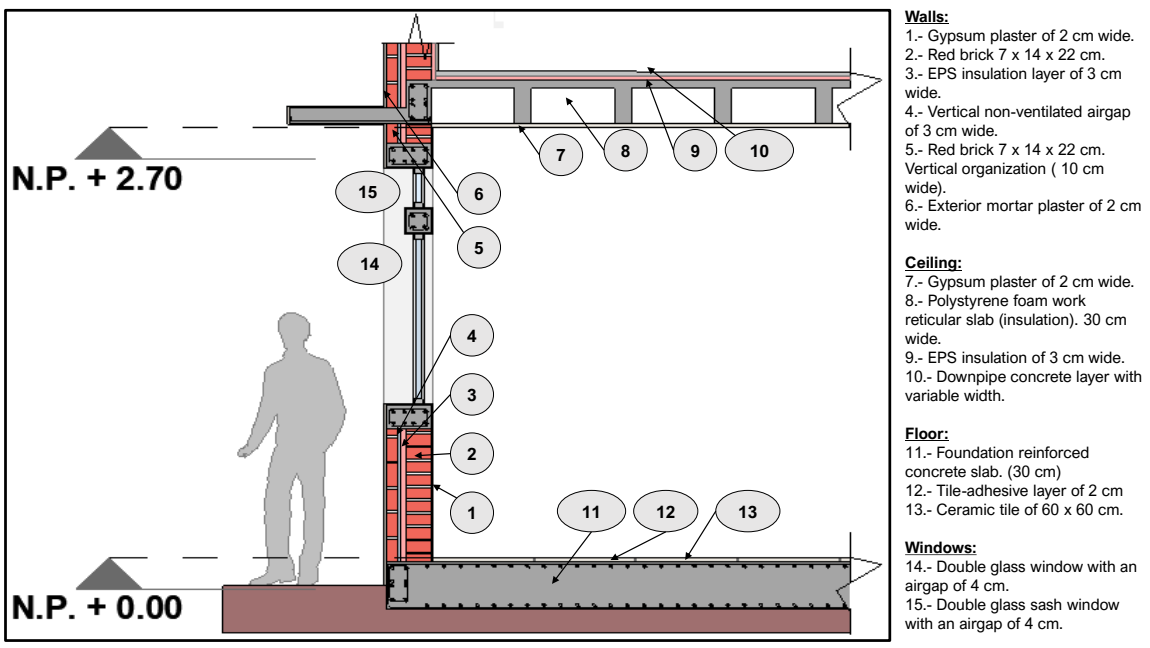

Figure A4. Construction details of the improved model of the W1 climatic zone, Merida. 


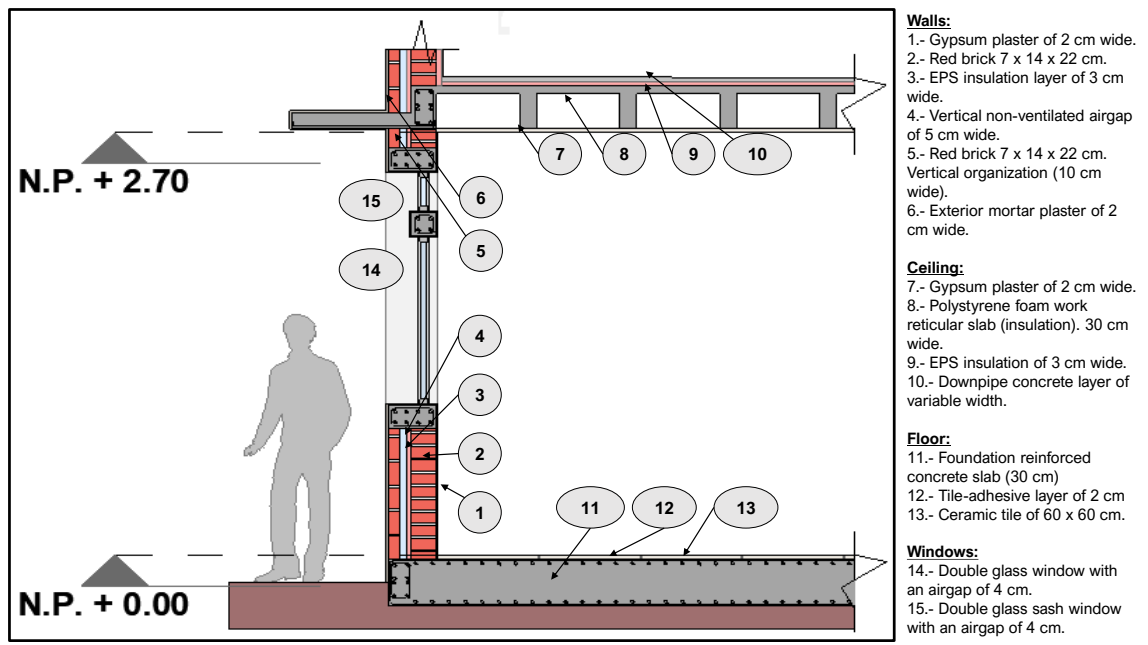

Figure A5. Construction details of the improved model of the $\mathrm{X} 1$ climatic zone, Campeche.
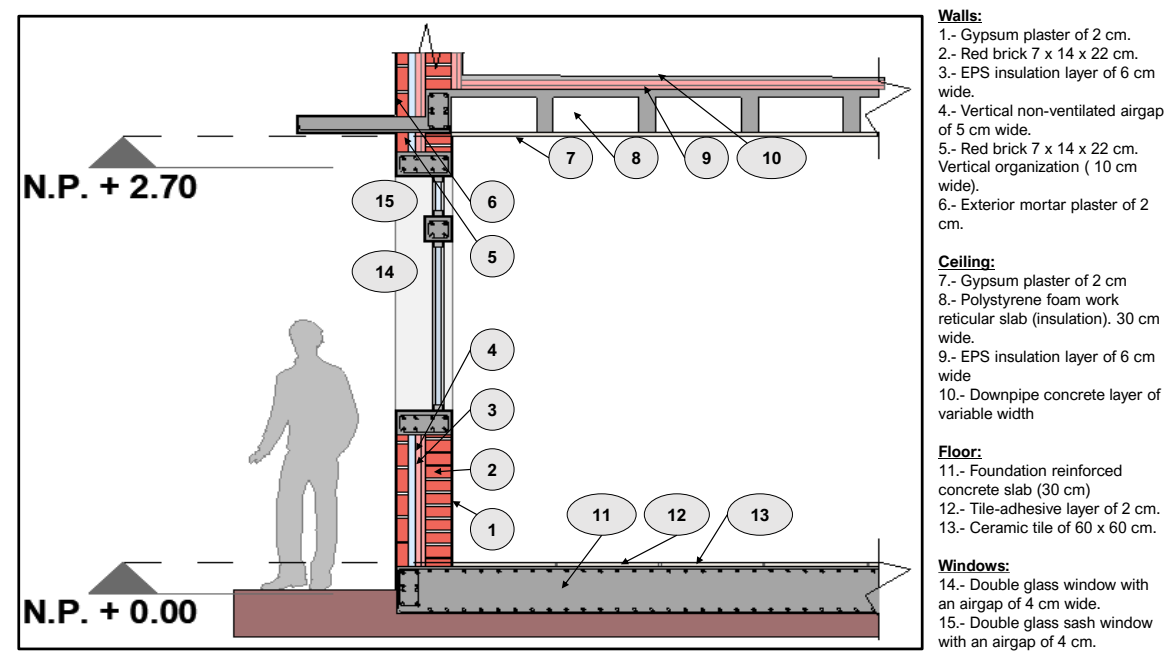

Figure A6. Construction details of the improved model of the Y1 climatic zone, Culiacan.
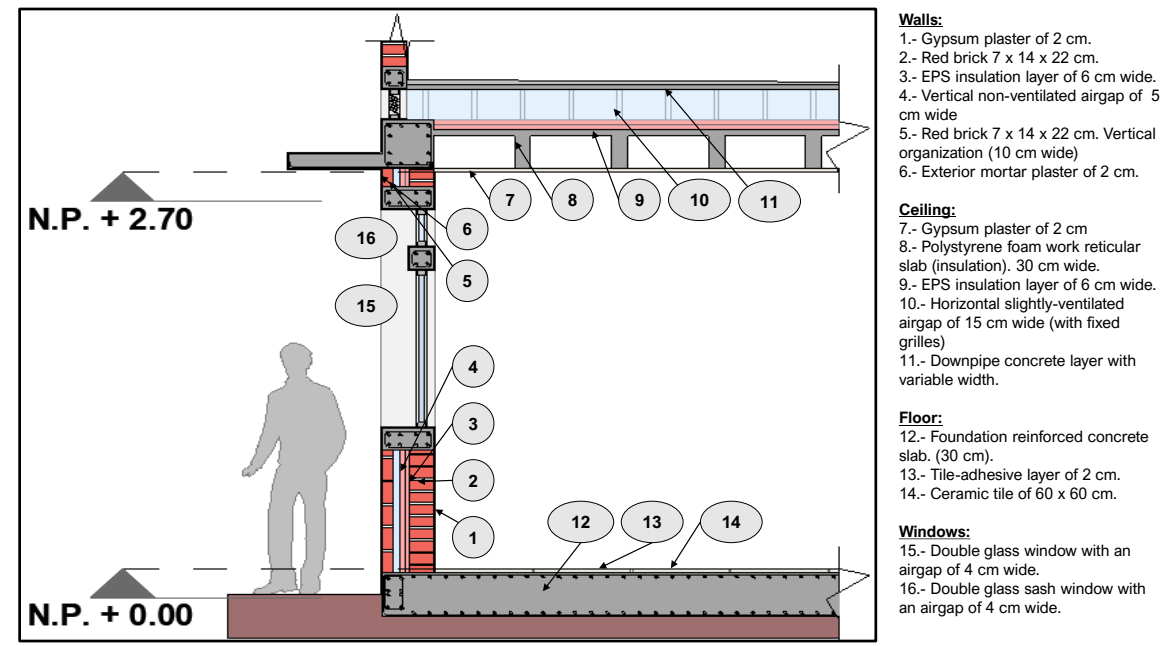

Figure A7. Construction details of the improved model of the Z2 climatic zone, Mexicali. 


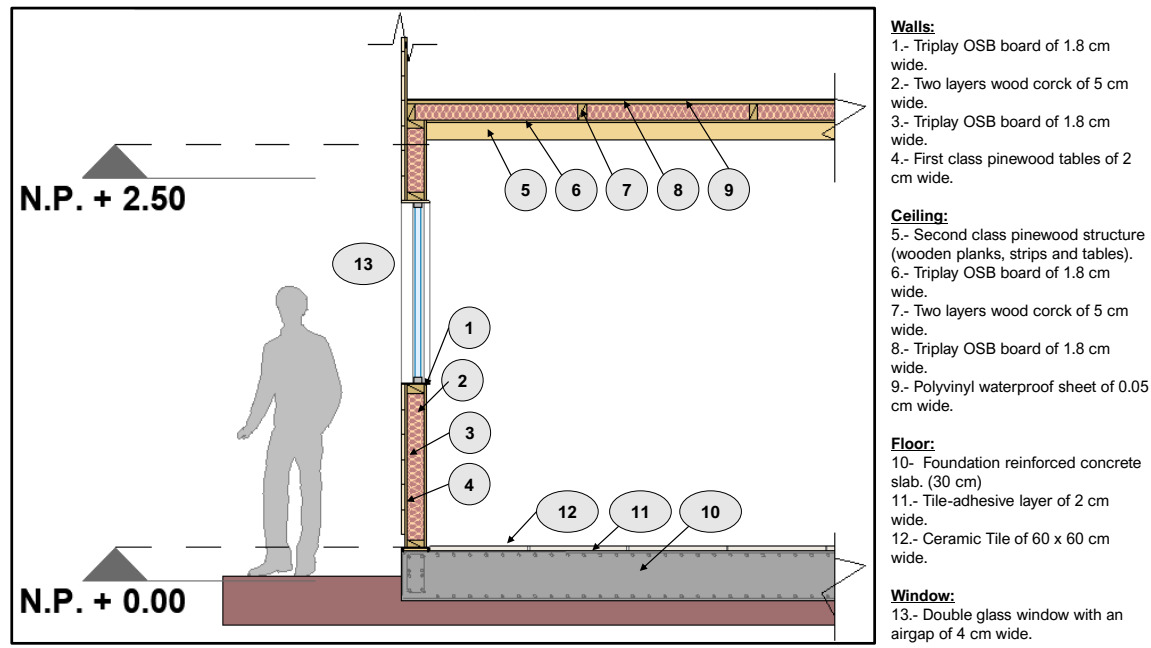

Figure A8. Construction details of the improved model for the wood-cork system.
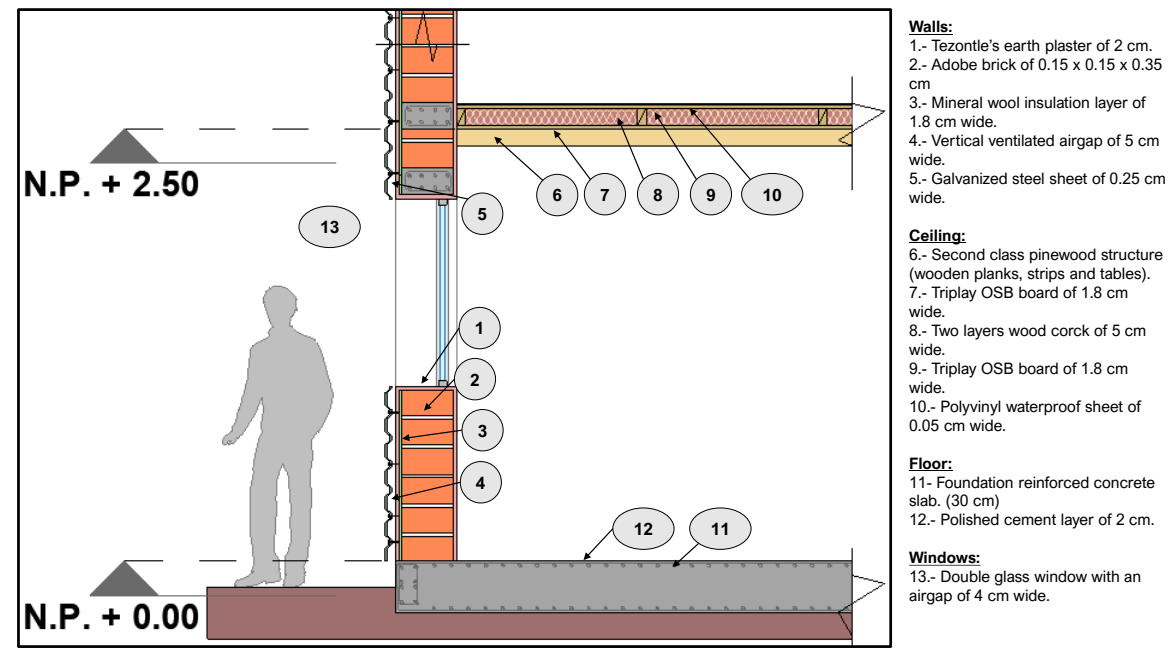

Figure A9. Construction details of the improved model for the adobe (mud and straw) and galvanized steel system.

\section{References}

1. Chávez, V. INFONATIV Tiene 100 mil Viviendas Abandonadas y en Litigio por Falta de Pago. El Financiero. 2017. Available online: https:/ / rebrand.ly / elfinanciero_infonavit100viviendas (accessed on 15 May 2020).

2. Griego, D.; Krarti, M.; Hernández-Guerrero, A. Optimization of energy efficiency and thermal comfort measures for residential buildings in Salamanca, Mexico. Energy Build. 2012, 54, 540-549. [CrossRef]

3. Diario Oficial de la Federación. Norma Oficial Mexicana de Eficiencia Energética en Edificaciones NOM-020-ENER-2011. Mexico. 2011. Available online: https:/ / rebrand.ly/nom020ener2011 (accessed on 15 May 2020).

4. Du, H.; Bandera, C.F.; Chen, L. Nowcasting Methods for Optimising Building Performance. 2019. Available online: http: / /www.ibpsa.org/proceedings/BS2019/BS2019_210777.pdf (accessed on 11 October 2020)

5. Fernández Bandera, C.; Pachano, J.; Salom, J.; Peppas, A.; Ramos Ruiz, G. Photovoltaic Plant Optimization to Leverage Electric Self Consumption by Harnessing Building Thermal Mass. Sustainability 2020, 12, 553. [CrossRef]

6. Lucas Segarra, E.; Du, H.; Ramos Ruiz, G.; Fernández Bandera, C. Methodology for the quantification of the impact of weather forecasts in predictive simulation models. Energies 2019, 12, 1309. [CrossRef]

7. LCADA. Manual Técnico Para la Aplicacion de la NOM-020-ENER-2015. CONUEE. 2015. Available online: https://rebrand.ly/ guiacalculoNOM_020_ENER_2011 (accessed on 5 October 2020).

8. Negrete Prieto, R.; Romo Anaya, M. Cuantificando a la clase media en México en la primera década del siglo XXI: Un ejercicio exploratorio. Real. Datos Y Espacio. Rev. Int. Estad. Y Geogr. 2014, 5, $62-95$.

9. Norma Mexicana NMX-AA-164-SCFI-2013: Edificación Sustentable-Criterios y Requerimientos Ambientales Mínimos; SEMARNAP: Mexico, 2013; p. 158. Available online: https://biblioteca.semarnat.gob.mx/janium/Documentos/Ciga/agenda/DOFsr/DO315 6.pdf (accessed on 10 October 2020). 
10. INFONAVIT. Hipoteca Verde. Mexico. 2017. Available online: https:// rebrand.ly/INFONAVIThipotecaverde (accessed on 15 May 2020).

11. INEGI. ENCEVI 2018: Primera Encuesta Nacional sobre Consumos de Energéticos en Viviendas Particulares. 2019. Available online: https:/ / rebrand.ly/encuestaENCEVI2018 (accessed on 8 May 2020).

12. Crawley, D.B.; Lawrie, L.K.; Winkelmann, F.C.; Buhl, W.F.; Huang, Y.J.; Pedersen, C.O.; Strand, R.K.; Liesen, R.J.; Fisher, D.E.; Witte, M.J.; et al. EnergyPlus: Creating a new-generation building energy simulation program. Energy Build. 2001, 33, 319-331. [CrossRef]

13. ASHRAE. ASHRAE fundamentals handbook. In American Society of Heating Refrigeration and Air-Conditioning Engineers; ASHRAE: Atlanta, GA, USA, 2001.

14. Segarra, E.L.; Ruiz, G.R.; González, V.G.; Peppas, A.; Bandera, C.F. Impact Assessment for Building Energy Models Using Observed vs. Third-Party Weather Data Sets. Sustainability 2020, 12, 6788. [CrossRef]

15. Han, J.; Bae, J.; Jang, J.; Baek, J.; Leigh, S.B. The Derivation of Cooling Set-Point Temperature in an HVAC System, Considering Mean Radiant Temperature. Sustainability 2019, 11, 5417. [CrossRef]

16. Yuan, J.; Emura, K.; Farnham, C. Effects of recent climate change on hourly weather data for HVAC design: A case study of Osaka. Sustainability 2018, 10, 861. [CrossRef]

17. Zepeda, R.V. Las Regiones Climáticas de México 1.2. 2; Universidad Nacional Autonoma de Mexico: Mexico City, Mexico, 2005; Volume 2.

18. Liverman, D.M.; O’Brien, K.L. Global warming and climate change in Mexico. Glob. Environ. Chang. 1991, 1, 351-364. [CrossRef]

19. Bai, L.; Wang, S. Definition of new thermal climate zones for building energy efficiency response to the climate change during the past decades in China. Energy 2019, 170, 709-719. [CrossRef]

20. Catálogo de Casas INFONATIV. INFONAVIT Web Page. 2020. Available online: https://rebrand.ly/catalogoinfonavit2020 (accessed on 8 May 2020).

21. EFINOVATIC: Certificación Energética de Edificios. EFINOVATIC Web Page. 2020. Available online: https://www.efinovatic.es/ energyPlus / (accessed on 15 May 2020).

22. Pascual Busain, M.A. SG SAVE Software v.2.8.0.2; EFINOVATIC: Pamplona, Spain, 2019.

23. Repository of Free Climate Data for Building Performance Simulation. Climate One Building Web Page. 2017. Available online: http: / / climate.onebuilding.org/ (accessed on 15 May 2020).

24. Climate Consultant Software v.6.0.; U.S. Deparment of Energy: Washington, DC, USA, 2016.

25. Gavilán Casal, A. Análisis Comparativo de la Eficiencia Energética en Edificios Existentes con Diferentes Herramientas de Simulación Energética. Facultad de Ingenieria Industrial. PhD's Thesis, Universidad de Valladolid, Valladolid, Spain, 2015.

26. Forbes. 9 de Cada 10 Mexicanos Quiere Comprar una Casa, 45 no Tiene Recursos. Forbes Economía y Finanzas. 2018. Available online: https: / / www.forbes.com.mx/9-de-cada-10-mexicanos-quiere-comprar-una-casa-45-no-tiene-recursos / (accessed on 8 May 2020).

27. INEGI. Encuesta Nacional de Ingresos y Gastos de los Hogares 2018: ENIGH. 2019. Available online: https://rebrand.ly/ EnighencuestaINEGI (accessed on 8 May 2020).

28. Gálligo, P.L. Un Techo Para Vivir: Tecnologías Para Viviendas de Producción Social en América Latina; Univ. Politèc. de Catalunya: Catalunya, Spain, 2005; Volume 1.

29. Oregon State University. When Is Asbestos Dangerous? Environmental Health and Safety Web Page. 2020. Available online: https: / / ehs.oregonstate.edu/asb-when (accessed on 28 May 2020).

30. García, A.K. 14 Millones de Viviendas en México no Son Dignas. El Economista. 2020. Available online: https://rebrand.ly/ economista14mviviendasnodignas (accessed on 28 May 2020).

31. National Renewable Energy Laboratory. Openstudio Software v.2.7.0; USA Department of Energy: Washington, DC, USA, 2019.

32. EUR-LEX. Council Directive 92:75:EEC of 22 September 1992 on the Indication by Labelling and Standard Product Information of the Consumption of Energy and Other Resources by Household Appliances. 1992. Available online: https://eur-lex.europa.eu/ legal-content/EN/ALL/?uri=CELEX\%3A31992L0075 (accessed on 20 November 2020).

33. Contreras, M. ITOM: Herramienta de Cumplimiento de las NOMs. Youtube Video Platform. 2019. Available online: https: / / youtu.be/-7GFACJU-wo (accessed on 10 June 2020).

34. Bienvenido-Huertas, D. Analysis of the Impact of the Use Profile of HVAC Systems Established by the Spanish Standard to Assess Residential Building Energy Performance. Sustainability 2020, 12, 7153. [CrossRef]

35. Código Técnico Español: Documento Básico HE-Ahorro de Energía 2019. Secretaria de Estado de Infraestructuras, Transporte y Vivienda. Ministerio de Fomento, Spain. 2019. Available online: https://rebrand.ly/codigotecnicoespanol2019 (accessed on 10 June 2020).

36. Gumbarević, S.; Burcar Dunović, I.; Milovanović, B.; Gaši, M. Method for Building Information Modeling Supported Project Control of Nearly Zero-Energy Building Delivery. Energies 2020, 13, 5519. [CrossRef]

37. Heywood, H. 101 Rules of Thumb for Low Energy Architecture; Routledge: Abingdon-on-Thames, UK, 2019.

38. CONAFOR. Manual de Auto-Construcción de Vivienda con Madera, Mexico. 2000. Available online: https://rebrand.ly/ CONAFORmanualviviendamadera (accessed on 10 June 2020).

39. Correa Giraldo, V. El Bahareque, un Sistema Constructivo Sismorresistente y Sustentable Para Soluciones de Vivienda Social en México. Research Gate Web Page. 2014. Available online: https:/ / rebrand.ly/baharequesismoresistente (accessed on 10 June 2020). 
40. HOME DEPOT Construction Materials Digital Catalogue. Home Depot Web Page. 2020. Available online: https://www. homedepot.com.mx/materiales-de-construccion (accessed on 15 June 2020).

41. Turley, C.; Jacoby, M.; Pavlak, G.; Henze, G. Development and Evaluation of Occupancy-Aware HVAC Control for Residential Building Energy Efficiency and Occupant Comfort. Energies 2020, 13, 5396. [CrossRef]

42. Ahn, J. Improvement of the Performance Balance between Thermal Comfort and Energy Use for a Building Space in the Mid-Spring Season. Sustainability 2020, 12, 9667. [CrossRef]

43. Zhai, Z.J.; Previtali, J.M. Ancient vernacular architecture: Characteristics categorization and energy performance evaluation. Energy Build. 2010, 42, 357-365. [CrossRef]

44. Oropeza-Perez, I.; Østergaard, P.A. Energy saving potential of utilizing natural ventilation under warm conditions—A case study of Mexico. Appl. Energy 2014, 130, 20-32. [CrossRef]

45. Lara, R.A.; Naboni, E.; Pernigotto, G.; Cappelletti, F.; Zhang, Y.; Barzon, F.; Gasparella, A.; Romagnoni, P. Optimization tools for building energy model calibration. Energy Procedia 2017, 111, 1060-1069. [CrossRef]

46. Soutullo, S.; Giancola, E.; Sánchez, M.N.; Ferrer, J.A.; García, D.; Súarez, M.J.; Prieto, J.I.; Antuña-Yudego, E.; Carús, J.L.; Fernández, M.Á.; et al. Methodology for Quantifying the Energy Saving Potentials Combining Building Retrofitting, Solar Thermal Energy and Geothermal Resources. Energies 2020, 13, 5970. [CrossRef]

47. Fregonara, E. Methodologies for supporting sustainability in energy and buildings. The contribution of Project Economic Evaluation. Energy Procedia 2017, 111, 2-11. [CrossRef]

48. Autodesk. About Energy Analysis for Autodesk ${ }^{\circledR}$ Revit ${ }^{\circledR}$. Autodesk Knowledge Network Webpage. 2017. Available online: https:/ / rebrand.ly/jhg2x (accessed on 15 May 2020).

49. García-Alvarado, R.; González, A.; Bustamante, W.; Bobadilla, A.; Muñoz, C. Características relevantes de la simulación energética de viviendas unifamiliares. Inf. Constr. 2014, 66, 005. [CrossRef]

50. Lolli, N.; Fufa, S.M.; Inman, M. A parametric tool for the assessment of operational energy use, embodied energy and embodied material emissions in building. Energy Procedia 2017, 111, 21-30. [CrossRef]

51. Mexico, G.B.C. Mexico Green Building Council Webpage: Aims and Projects. 2021. Available online: https://www.gbci.org/ mexico (accessed on 20 January 2021).

52. Sánchez, C.G. ¿Qué es y Que se Obtiene Con la Edificación Sustentable? CMIC Web Page. 2013. Available online: https: //rb.gy/hsqjicw (accessed on 20 January 2021). 